This is a postprint version of the following published document:

Galán, J.E. and Pollitt, M.G. Inefficiency persistence and heterogeneity in Colombian electricity utilities. Energy Economics, November 2014, v. 46, pp. 31-44. Avalaible in: http://dx.doi.org/10.1016/j.eneco.2014.08.024

(c) Elsevier

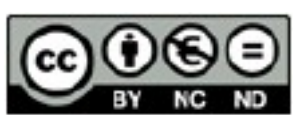

This work is licensed under a Creative Commons Attribution-NonCommercialNoDerivatives 4.0 International License. 


\title{
Inefficiency persistence and heterogeneity in Colombian electricity utilities ${ }^{\text {th }}$
}

\author{
Jorge E. Galán ${ }^{\mathrm{a}, *}$, Michael G. Pollitt ${ }^{\mathrm{b}}$ \\ a Department of Statistics, Universidad Carlos III de Madrid, Spain \\ b Energy Policy Research Group and Judge Business School, University of Cambridge, UK
}

\begin{abstract}
A B S T R A C T
The electricity reform in Colombia has exhibited gains in terms of reliability but its effects on firm efficiency and service quality have not been clear. Previous studies evaluating the performance of distribution companies after the reform have not found evidence of improvements, although large differences in efficiency have been found among firms. This suggests high inefficiency persistence and heterogeneity in the Colombian distribution sector. In this paper, we propose an extension of dynamic stochastic frontier models that accounts for unobserved het erogeneity in the inefficiency persistence and in the technology. The model incorporates total expenses, service quality and energy losses in an efficiency analysis of Colombian distributors over fifteen years after the reform. We identify the presence of high inefficiency persistence in the sector, and important differences between firms. In particular, rural companies and firms with small customers present low persistence and evidence the largest gains in efficiency during the period. However, increases in efficiency are only manifested during the last five years when the main improvements in service quality and energy losses are presented. Overall, inefficiency persistence, customer density and consumption density are found to be important criteria to be considered for regulatory purposes.
\end{abstract}

\section{Introduction}

The electricity market reform introduced in Colombia in 1994 established a new structure of the sector and new conditions for private participation and competition. The reform was mainly motivated by an energy crisis suffered in 19921993 that caused major blackouts as a consequence of extreme droughts. This situation revealed the ineffi ciency and inability of the state owned industry to satisfy an increasing demand and to deal with weather events. The regulatory reform adapted a version of the UK model with the creation of a pool where prices are settled in a bidding process. The Electric Law of 1994 created the regulatory commission Comisión Reguladora de Energía y Gas (CREG) and split the traditional vertically integrated and monopolistic system into the activities of generation, transmission, distribution and retailing.

\footnotetext{
is Jorge E. Galán acknowledges from the Energy Policy Research Group at the University of Cambridge and the financial support Spanish Ministry of Education and Science, research project ECO2012-3401. Data sent by Comisión Reguladora de Energía y Gas is also gratefully acknowledged.

* Corresponding author at: Department of Statistics, Universidad Carlos III de Madrid, C/ Madrid 126, 28903 Getafe, Spain. Tel.: + 34 916249674; fax: + 34916249849.

E-mail address: jegalan@est-econ.uc3m.es (J.E. Galán).
}

As a consequence, the seven major public holdings in charge of multiple activities from generation to distribution previous to the reform were divested into eleven companies performing only one of these activities and two companies involved in both generation and distribution. Although generation and distribution were allowed to be performed by the same company, limits to the amount of electricity that the distributor could buy from its own generation firm were set and separate managerial and accounting procedures were required.

However, privatization and competition have been slow processes in Colombia. After the reform only two of the new companies were fully privatized and, although in the following years several companies were open to private capital, in most of the cases private investors are minority shareholders and firms remain under the control of municipal ities and regional governments. Certainly, privatization and competition have been identified as pending issues in Colombia in previous studies analyzing the effects of the first years of the reform (see Pombo \& Taborda, 2006; Larsen et al., 2004).

Nevertheless, these processes have accelerated in recent years. From 2010 to 2012, the number of generating and retailing firms has increased by $23 \%$ and $32 \%$, respectively, and most of the companies involved in these activities are classified as private owned. In distribu tion, companies with a majority of public capital account for $62 \%$ of the total firms and serve $51 \%$ of the total users. Currently there are 54 
generation, 33 distribution and 85 retailing companies. Of the generation firms, 12 are also involved in distribution and 15 combine generation exclusively with retailing activities. ${ }^{1}$

In general, the effects of the reform have been positive in terms of the ability of the electricity sector to overcome extreme weather con ditions and to satisfy the increasing demand. Since the reform, Colombia has not experienced blackouts in spiteof some severe droughts that have affected the region during the 19971998 and 20092010 periods, and that have seriously affected neighbor countries. Moreover, Colombiahas become an electricity exporter to Ecuador and Venezuela and it is currently planning to export electricity to other Central American and Caribbean countries. ${ }^{2}$

On the other hand, the effects of the reform in terms of energy losses and service quality have not been successful until recent years. During the first ten years of the reform, energy losses and electricity interrup tions did not present reductions and were even higher than previous to the reform. Colombia also exhibited a very bad performance in these aspects when compared to other countries in the region (see Larsen et al., 2004; Dyner et al., 2006). Only from 2008, important reductions in energy losses can be observed. In terms of the length of interruptions, although it is possible to identify some improvements since 2005, it is only until 2011 that significant reductions are evident. In both cases, these improvements are consequence of changesin the regulation, as is discussed further below.

Meeting the quality requirements and satisfying the increases in electricity consumption and users has required distribution companies to make important investments. In fact, capital and operational expenses have increased by more than 30\% during the period 1998 2012. This suggests the need to study the effects of the reform and the latest regulations established by CREG on efficiency. Concerning this issue, some few previous studies have quoted the effects on efficiency of the reform in Colombia and no major gains have been identified. Pombo \& Taborda (2006) use Data Envelopment Analysis (DEA) to per form an analysis of technical efficiency of Colombian distribution firms during the period from 1985 to 2001. The authors find no major changes during the period and highlight that the most efficient firms previous to the reform continue to be in the best practice frontier but firms which were inefficient have not been able to change this condition and present even lower efficiency scores. A similar result was found by Melo \& Espinosa (2005), who measure the technical efficiency of Colombian distributors from 1999 to 2003 using Stochastic Frontier Analysis (SFA). The authors found out that public companies perform better than those privately owned but that there have not been major changes in technical efficiency in the immediate years after the reform. This Colombian evidence contrasts with the effects of the electricity reforms on performance in other South American countries. In Chile and Argentina evidence has been found on important improvements in efficiency and service quality after the reforms (see Pollitt, 2004, 2008), for complete studies of the effects of the reforms in these coun tries, respectively. The case of Chile is interesting since its reform in 1982 was not only the first in the region but also the first in the world along with the U.K. In fact, as stated in Pollitt(2004) it has been recog nized as a successful example and has been used as a model for other privatizations in Latin America and around the world. In Brazil, the reform introduced in 1995 has been found to improve technical effi ciency during the post reform years by Mota (2003). Pérez Reyes \& Tovar (2009) also found increases in productivity and efficiency of distribution companies after the reform introduced in 1993.

Findings from these studies may suggest the presence of high adjust ment costs in the Colombian distribution sector that imply inefficiency to be highly persistent in time. In this context, it is costly for firms to

\footnotetext{
1 Information provided by the national supervisory agency of public services Superintendencia de Servicios Públicos Domiciliarios (SSPD) in 2013.

2 In 2011, Colombia exported 1.740 GWh. Information from the Ministry of Mines and Energy.
}

move towards optimal conditions and they may find it optimal to remain inefficient in the short run. These studies have also evidenced the existence of important differences among firms with different characteristics in terms of their performance.

Therefore, this work has two main aims: first, to identify the presence of adjustment costs in the distribution sector after the reform and distinguish heterogeneity in the technology and the inefficiency among Colombian distributors; second, to estimate measures of efficiency that consider costs and quality of service in the Colombian electricity sector and their evolution from the first years after the reform into the following fifteen years. In particular, we focus on the last five years, when most of the changes in terms of quality, demand and costs have occurred.

For these purposes we propose a dynamic heterogeneous SFA model, which extends other dynamic specifications in the frontier efficiency literature. In particular, we extend the dynamic model introduced by Tsionas (2006) in order to allow for heterogeneous persistence and unobserved technological heterogeneity. This allows us to identify differences in the adjustment costs faced by firms and to distinguish inefficiency properly from unobserved firm characteristics. Inference of the model is performed using the Bayesian approach and the effects of the proposed specification on efficiency estimations are evaluated.

The paper is divided into six sections including this introduction. In the second section, we describe the main characteristics of the Colombian electricity distribution sector after the reform. In the third section, we review previous literature on dynamic SFA models and het erogeneity in the electricity sector, and we present the proposed model, the estimation procedure and the model specification. In the fourth sec tion, we describe the data and the empirical model. In the fifth section, we analyze the estimation results. Finally, we present some conclusions.

\section{Colombian electricity distribution sector}

The activity of electricity distribution in Colombia is defined by CREG as the transportation of electricity from the national transmission system, which operates at voltages above $220 \mathrm{kV}$, to the final user. There are four different levels of tension operated by the distributor. That is, from level 1, which involves tension levels below $1 \mathrm{kV}$, to level 4 with tension levels between $57.5 \mathrm{kV}$ and $115 \mathrm{kV}$. CREG follows a cost of service type of regulation and establishes the pricing formula for distributors for each of the tension levels considering demand, investments, and administration, operation and maintenance costs. The length of the price review is five years and the first pricing period was 1998 2002. ${ }^{3}$

Besides prices, service quality and energy losses have also been under regulation. In 1998 CREG established maximum values for both duration and number of interruptions by tension level, as well as com pensations to users when companies exceeded these maximums. ${ }^{4}$ However, small and slow improvements motivated CREG to modify this scheme in 2008. The new regulation introduced quality incentives in the pricing formula and compensations for the most affected users. ${ }^{5}$ Under this model, an index of service discontinuity is calculated quar terly and three ranges of values for this index are set: if distribution companies exceed an acceptable range their pricing formula is revised down; if they perform better than the acceptable values their formula is revised up; and if their discontinuity index is within the acceptable range their formula does not change. The implementation of this mech anism has been postponed and only from 2011 have all companies had to report this index. The effects of this last regulatory scheme are still uncertain. In the literature, some studies have found this direct

\footnotetext{
3 CREG resolution 031 of 1997

4 CREG resolution 070 of 1998.

${ }^{5}$ CREG resolution 097 of 2008.
} 


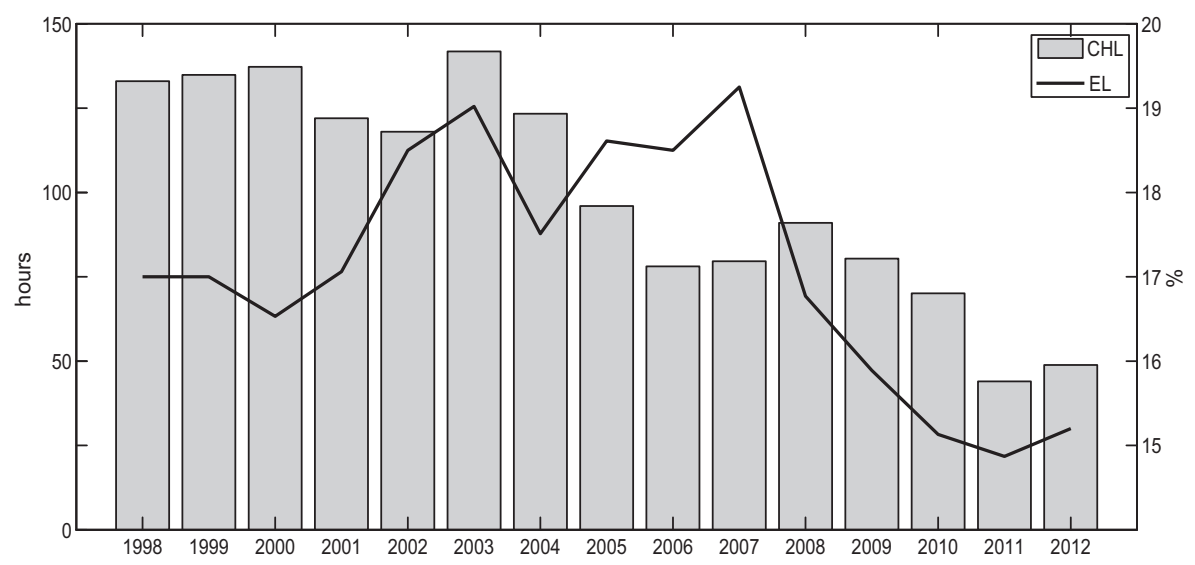

Fig. 1. Average customer hours lost (CHL) and energy losses (EL) per firm.

mechanism of incentive regulation to have negative effects on quality of service (see Ter Martirosyan \& Kwoka, 2010). However, the most important reductions in the length of interruptions have occurred since then. This can be observed in Fig. 1, where the evolution in customer hours lost (CHL) and energy losses (EL) from 1998 to 2012 is presented for the sample of distribution companies described in Section $4 .^{6}$

Regarding energy losses, new regulations were also set by CREG in 2008 by establishing a program for reducing losses and setting upper limits for the percentage of losses recognized by users via tariff. ${ }^{7}$ The effects of this regulation also seem to be positive (see Fig. 1).

During the period 1998 2012, the electricity consumption and the number of connected users have also presented important increases ( $27 \%$ and $51 \%$, respectively). Fig. 2 presents this evolution for the same firms above. We can observe that, after a period characterized by economic recession and low growth rates (1999 2003), consumption and customers exhibit an upward trend with high growth in the most recent years.

Satisfying the demand and meeting the quality requirements have had effects on the costs of distribution firms. Fig. 3 presents the evolu tion of capital and operational expenses in real US dollars of 2012 for the same companies in the figures above. We observe important increases, mainly in operational expenses, from 2007, when relatively higher capital expenses were made. The overall increase in real total expenses from 1998 to 2012 was 31\%.

Higher distribution costs have had an impact on the tariff for the final user. Fig. 4 plots the evolution of the tariff per kWh by decomposing it into each of their components. Although almost all the components of the tariff have increased in real terms, the proportion of the distribution component has raised from $33 \%$ to $40 \%$ during the period, with a particular increase in 2011 and 2012.

Regarding tariffs, it is important to remark that CREG establishes their value only for regulated users. After the reform, customers were separated into regulated and non regulated users, which are differ entiated in terms of their power demand and consumption. Since 2000, CREG has defined regulated users as those with power demands under $0.1 \mathrm{MW}$ and monthly consumption below $55 \mathrm{MWh} .^{8}$ Non regulated users are allowed to negotiate retail prices with retailing companies.

\section{Methodology}

Frontier efficiency models have become a very useful tool to study the impact of the deregulation processes carried out in many countries

\footnotetext{
${ }^{6} \mathrm{CHL}$ is the duration of service interruptions measured in hours per customer and EL is the percentage of energy lost due to technical reasons.

7 CREG resolutions 199 and 121 of 2007.

${ }^{8}$ CREG Resolution 131 of 1998.
}

from the 1990s and to analyze the performance of the participants in the different stages from generation to retailing. In particular, SFA, first introduced in Aigner et al. (1977) and Meeusen \& van den Broeck (1977) has the advantage of allowing inferences on the parameters and considering idiosyncratic errors, in contrast to the most common non parametric methods such as DEA. It also allows dealing easier with panel data structures and to model the evolution of efficiency over time. Two different approaches have been used in the literature for this purpose. The most common approach estimates the temporal pattern of the variation in inefficiency by using deterministic specifica tions of time. Here we find the proposals by Kumbhakar (1990), Battese \& Coelli (1992), Lee and Schmidt (1993), and Cornwell et al. (1990). These models have the problem of imposing arbitrary restrictions on the short run efficiency and they are not able to model firm leveldynamic behavior. A second approach proposed by Ahn et al. (2000) and Tsionas (2006) directly incorporates the dynamic behavior of the inefficiency by specifying an autoregressive structure that recog nizes inefficiency persistence over time. In particular, Tsionas (2006) ar gues that adjustment costs prevent firms from making instant adjustments towards optimal conditions and causes inefficiency persis tence. Rigidities derived from the nature of some inputs, regulations, transaction costs, information failures and other adjustment costs may cause firms to find it optimal to remain partly inefficient in the short run.

\subsection{Heterogeneity in the electricity sector}

Accounting for both observed and unobserved heterogeneity in sto chastic frontier models is still a concern since efficiency estimations are sensitive to the modeling of sources of heterogeneity. In the case of ob served heterogeneity, previous applications to the electricity distribu tion sector have studied the effects of including different types of covariates in the frontier, in the inefficiency or both. Hattori (2002) found out that heterogeneity sources related to the load factor, customer density and consumption density affect both, the shape of the frontier and the level of technical efficiency. Goto \& Tsutsui (2008) found only customer density to have impacts on the technical efficiency of US electricity distribution firms in a model that also includes consumption density, time and a deregulation index in the inefficiency distribution. In a recent study, Growitsch et al. (2012) considered weather factors and found them to be influential on costs but have limited effects in the efficiency estimations.

However, Growitsch et al. (2012) achieved more sensitivity in the efficiency estimations when unobserved heterogeneity is included by using a True Random Effects (TRE) model as proposed by Greene (2005). Other recent studies in electricity distribution have also been found to be relevant in considering this latent source of heterogeneity in SFA models. Kopsakangas Savolainen \& Svento (2011) perform a good analysis of the effect of observed and unobserved heterogeneity 


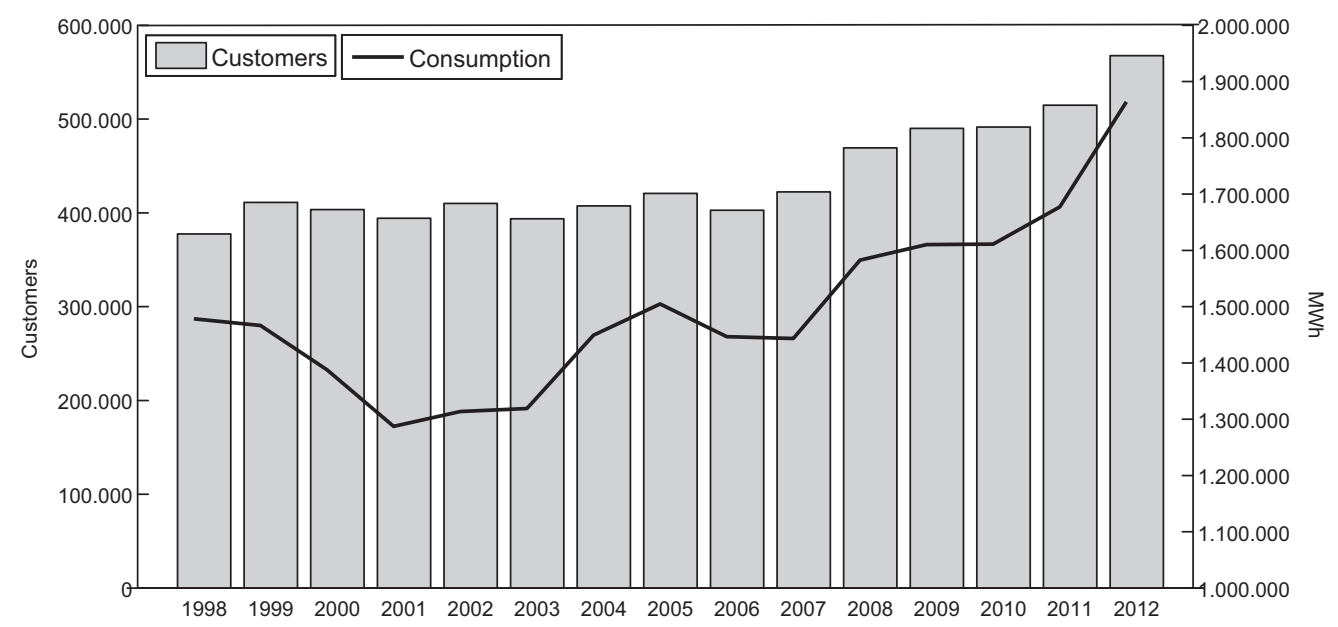

Fig. 2. Average number of customers and electricity consumption per firm.

and warn about the high changes produced in rankings of cost efficiency under different models.

In the context of dynamic inefficiency models, Emvalomatis et al. (2011) studied the effect of including technological unobserved hetero geneity in an application to power generation plants in the US. Their findings reveal high persistence of inefficiency overtime but also biases in the efficiency estimations when unobserved factors are not consid ered. However, it is also possible to think of heterogeneity regarding the persistence parameters. This would be related to possible differ ences in the adjustment costs among firms. The only studies considering this issue have been applications to the banking sector, where this type of heterogeneity has been found to be relevant (see Huang \& Chen, 2009; Galán et al., in press). ${ }^{9}$

\subsection{A dynamic heterogeneous model}

We propose a dynamic stochastic frontier model that accounts for both observed and unobserved heterogeneity sources. This is mainly an extension of the model introduced by Tsionas (2006) that combines it with other recent proposals in the literature of dynamic SFA models. In particular, the proposed specification accounts for observed firm characteristics in the inefficiency dynamics, as in Tsionas (2006), but also captures two additional sources of unobserved heterogeneity: the first one is related to differences in the adjustment costs among firms, and we model it through a heterogeneous persistence parameter as in Galán et al. in press; the second one is related to unobserved sources of technological heterogeneity and we model it in a similar way to the dynamic model in Emvalomatis (2012). The general model is given by the following equations:

$y_{i t} \quad \alpha_{i}+\mathbf{x}_{i t} \beta+v_{i t}-u_{i t}, \quad v_{i t} \sim N\left(0, \sigma_{v}^{2}\right)$

$\log u_{i t} \quad \omega+\mathbf{z}_{i t} \gamma+\rho_{i} \log u_{i, t}{ }_{1}+\xi_{i t}, \quad \xi_{i t} \sim N\left(0, \sigma_{\xi}^{2}\right), \quad t \quad 2 \ldots T$

$\left.\log u_{i 1} \quad \frac{\omega+\mathbf{z}_{i t} \gamma}{1-\rho_{i}}+\xi_{i 1}, \quad \xi_{i 1} \sim N \quad 0, \frac{\sigma_{\xi}^{2}}{1-\rho_{i}^{2}}\right), t \quad 1$

\footnotetext{
${ }^{9}$ Huang \& Chen (2009) include firm specific persistence parameters in the context of models with forward-looking rational expectations while Galán et al. in press include them in relation to the theory of adjustment costs.
}

Eq. (1) represents the stochastic frontier, where in the case of a production function $y_{i t}$ is the output for firm $i$ at time $t, \alpha_{i}$ is the firm specific parameter intended to capture unobserved technological heterogeneity, $\mathbf{x}_{i t}$ is a row vector of the input quantities, $\beta$ is a vector of parameters, $v_{i t}$ is the idiosyncratic error assumed to follow a normal distribution, and $u_{i t}$ is the inefficiency component. The dynamic specifi cation for the inefficiency is represented by (2), where $\omega$ is a constant term, $\mathbf{z}_{i t}$ is a row vector of firm specific heterogeneity variables, $\gamma$ is a vector of parameters, $\rho_{i}$ is the heterogeneous persistence parameter capturing, for every firm, the proportion of inefficiency that is transmit ted from one period to the next, and $\xi_{i t}$ is a white noise process with con stant variance $\sigma_{\xi}^{2}$, which may capture unobserved random shocks in the dynamic component. Finally, Eq. (3) represents the specification of the inefficiency in the first period and is intended to initialize a stationary dynamic process.

Stationarity is imposed by requiring the persistence parameters to satisfy $\left|\rho_{i}\right|<1$. This is important in order to avoid possible divergence of $\log u_{i t}$ to positive or negative infinity, which would lead to efficiencies equal to zero or to one. These results are not desirable since in the first case they would mean that completely inefficient firms remain in the market, and in the second case that firms may be fully efficient, contra dicting the adjustment cost theory behind the formulation. In general, if a firm has a value of $\rho_{i}$ close to 1 it would suggest that this firm presents high adjustment costs, which translates into a high proportion of ineffi ciency being transmitted from one period to the next. On the other hand,if this value is close to 0 , a low proportion of inefficiency is persis tent in time, implying that the firm may move quicker towards more optimal conditions.

The general model in (2) and (3) allows to evaluate different speci fications by imposing restrictions over some parameters. If $\alpha_{i}=\alpha$ is assumed, then unobserved technological heterogeneity is not accounted for. If $\rho_{i}=\rho$ is imposed, homogeneous persistence is assumed for all companies in the sector. If $\rho=0$ the model reduces to a static model where the inefficiency follows a log normal distribution with firm specific mean. Finally, if no inefficiency covariates are observed, then $\gamma=0$ would be assumed.

\subsection{Bayesian inference}

Inference of the model in (1) till (3) is carried out using the Bayesian approach. Bayesian inference of stochastic frontier models was intro duced by van den Broeck et al. (1994) and allows incorporating formally parameter uncertainty and obtaining posterior distributions of ineffi ciencies for every observation. 


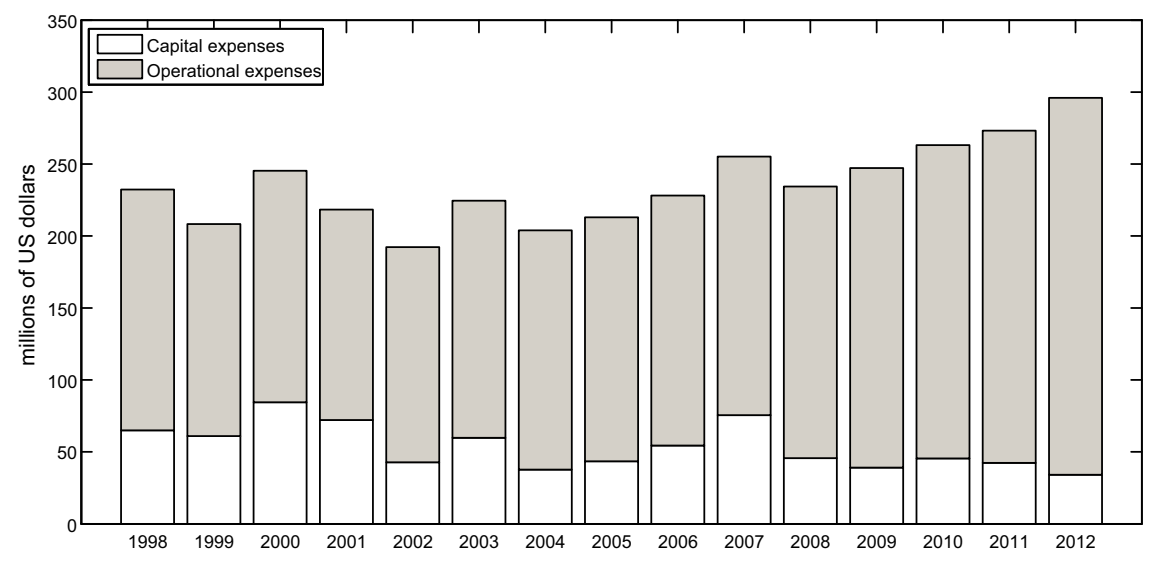

Fig. 3. Average operational and capital expenses per firm.

In general, we assume non informative but proper prior distribu tions for all the parameters. For the parameter capturing unobserved heterogeneity in the frontier we define a hierarchical structure where $\alpha_{i} \sim N\left(\alpha, \lambda_{\alpha_{i}}{ }^{1}\right)$ and the hyperparameter $\alpha \sim N\left(0, \lambda_{\alpha}^{-1}\right)$. Priors for the precision parameters $\lambda$ are set to 0.1 and 0.001 for the firm specific parameters and the hyperparameter, respectively. For parameters in $\beta$ we assume a normal prior distribution $\beta \sim N\left(0, \Lambda_{\beta}^{-1}\right)$ where $\Lambda_{\beta}$ is a precision diagonal matrix with priors set to 0.001 for all parameters. The variance of the idiosyncratic error component is assumed to follow an inverse gamma distribution $\sigma_{v}^{2} \sim I G(a, b)$ with priors set to 0.01 and 100 for the shape and scale parameters.

The inefficiency component as defined in (2) follows a $\log$ normal distribution where $u_{i t} \mid u_{i, t-1}, \omega, \mathbf{z}_{i t}, \gamma, \rho_{i}, \sigma_{\xi}^{2} \sim L N\left(\omega+\mathbf{z}_{i t} \gamma+\right.$ $\left.\rho_{i} \log u_{i, t-1}, \sigma_{\xi}^{2}\right)$ for $t=2 \ldots T$. For $t=1$, the inefficiency is distributed $u_{i 1} \mid \omega, \mathbf{z}_{i 1}, \gamma, \rho_{i}, \sigma_{\xi}^{2} \sim L N\left(\frac{\omega+z_{i j} \gamma}{1} \rho_{i}, \frac{\sigma_{\xi}^{2}}{1} \rho_{i}^{2}\right)$.

Regarding the parameters in the inefficiency, the distribution for the common constant term is $\omega \sim N\left(\mu_{\omega}, \lambda_{\omega}^{-1}\right)$ with priors set to -1.5 and 1 for the mean and precision parameters, respectively. The distribution for the parameters of observed heterogeneity is: $\gamma \sim N\left(0, \Lambda_{\gamma}^{-1}\right)$ where $\Lambda_{\gamma}^{-1}$ is a diagonal matrix of precisions with priors set to 0.1 for every precision parameter. For the persistence parameters, we impose $\left|\rho_{i}\right|<1$ to assure stationarity and we define a hierarchical structure with $\rho_{i}=2 k_{i}-1$, where $k_{i} \sim \beta(k, 1-k)$. The hyperparameter is distributed $k \sim \beta(r, s)$ with priors set to 0.5 for shape parameters. The variance of the inefficiency component is assumed to follow an inverse gamma distribution where $\sigma_{\xi}^{-2} \sim G(n, d)$ with priors set to 10 and 0.01 for the shape and scale parameters, respectively. ${ }^{10}$

Sensitivity analysis is performed on priors in the inefficiency compo nent. Different values are used for prior parameters in the distributions of $\omega, k$ and $\sigma_{\xi}^{2}$ and posterior results are found to converge to approxi mately the same values. ${ }^{11}$

The specification proposed accounts for firm specific effects in the frontier and the inefficiency persistence. However, firms in the sector share a common long run dynamic component $\omega$, common elasticities for the covariates given by $\gamma$, and are linked through common parame ters $\rho$ and $\alpha$ that are present in the hierarchical structures defined.

As introduced by Koop et al. (1995), Markov Chain Monte Carlo (MCMC) methods and, in particular, the Gibbs Sampling algorithm with data augmentation can be used. We carry out the implementation of the proposed model using the WinBUGS package (see Griffin \& Steel, 2007, for a general procedure in applications to SFA). For all the estimated models we use 5000 iterations for posterior inference. The

\footnotetext{
10 This is the same prior used by Tsionas (2006) and Galán et al. in press.

11 The priors used center the efficiency prior distributions at 0.8 .
}

MCMC algorithm involves 50,000 iterations with 10,000 discarded in a burn in phase and a thinning equal to 8 is used to remove autocorrelations.

Sensitivity analysis was performed by allowing changes in the priors of the parameters in the inefficiency component. We examined sensitivity to small changes in the values of $n$ and $d$ in the priors of $\sigma_{\xi}^{-2}$ with no evidence of posterior sensitivity. For the persistence parameter $\rho$ we studied the sensitivity to the use of a truncated normal distribution and posterior results were found to be robust to the use of this alternative. Finally, we also studied changes in priors of $\omega$ since they imply different priors on the efficiency but no important differences were obtained in the posterior distributions. Fig. A.1 in the Appendix presents prior and posterior distributions from some of these experiments.

\subsubsection{Comparison criteria}

Using the MCMC output, we compare the different models derived from (1) till (3) using a robust version of the Deviance Information Criterion (DIC) and a criterion for predictive performance, which is the Log Predictive Score (LPS). ${ }^{12}$

$D I C$ is a within sample measure of fit introduced by Spiegelhalter et al. (2002) and defined as: DIC $2 \overline{D(\theta)}-D(\bar{\theta})$ with $D(\theta)=-2 \log f(\mathbf{y} \mid \theta)$, where $D(\theta)$ defines the deviance of a model with parameters $\theta$ and data y. The version of this criterion used here is the $D I C_{3}$, as developed in Richardson (2002) and Celeux et al. (2006), and its formulation is the following:

$D_{I C} \quad-4 E_{\theta}[\log f(\mathbf{y} \mid \theta) \mid \mathbf{y}]+2 \log \hat{f}(\mathbf{y})$.

This alternative uses an estimator of the density $f(\mathbf{y} \mid \theta)$ instead of the posterior mean $\bar{\theta}$ and has been found to be more stable in models with random effects, mixtures and with data augmentation (see Li et al., 2012).

We also implement a criterion for evaluating out of samplebehavior of the models, which is LPS. This criterion was first introduced by Good (1952)and is intended to examine model performance by comparing its predictive distribution with out of sample observations. For this pur pose the sample is split into a training and a prediction set. Our prediction set consists of observations corresponding to the last two observed years of every firm in the sample, and the training set contains all the rest. The formula is the following:

LPS $\quad-\frac{1}{k} \sum_{i}^{k} \log f\left(y_{i, t_{i}} \mid\right.$ previous data $)$,

12 Applications of both criteria to Bayesian SFA models can be found in Ferreira \& Steel (2007), Galán et al. (2014), and Griffin \& Steel (2004). 


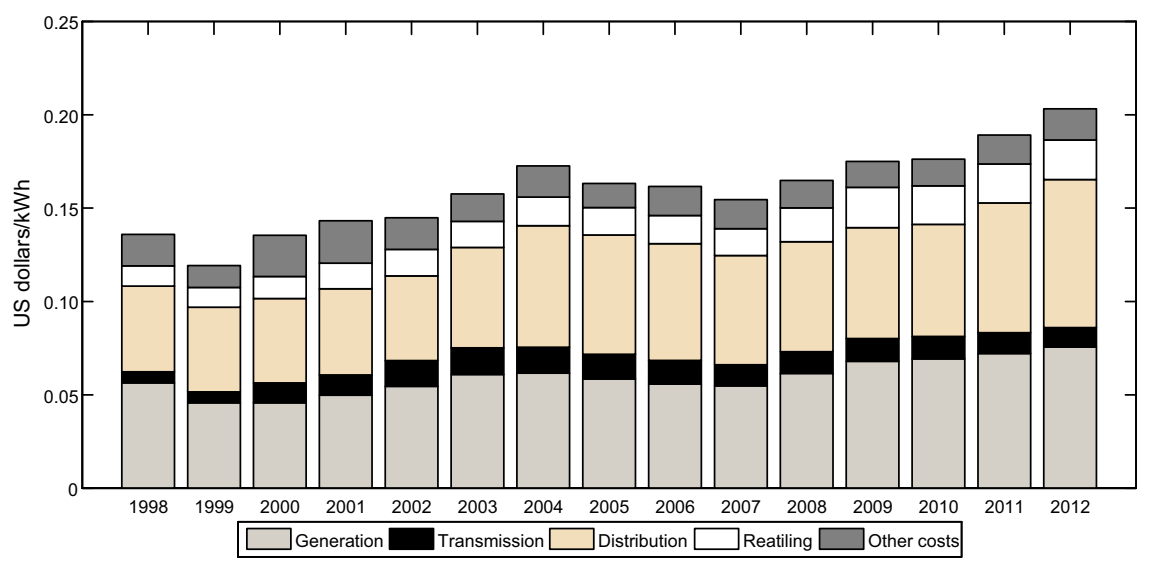

Fig. 4. Evolution of tariff per kWh in Colombia in real terms of 2012.

where $y_{i, t_{i}}$ represents the observations in the predictive set for the $k$ firms in the sample and $t_{i}$ represents the penultimate time point with observed data for firm $i$.

\subsection{Stochastic input distance function}

Given that electricity distributors do not have control over electricity consumption and the number of users, which are their natural outputs, it is only possible to use input oriented models for measuring technical efficiency. In this context, we assume that distribution firms use an $N \times 1$ vector of inputs $\mathbf{x}=\left(x_{1}, x_{2}, \ldots, x_{N}\right)^{\prime}$ to provide an $M \times 1$ vector of outputs $\mathbf{q}=\left(q_{1}, q_{2}, \ldots, q_{M}\right)^{\prime}$. Thus, we define an input set as follows:

$L_{g}(q) \quad \mathbf{X}: \mathbf{X}$ and technology $g$ can produce $\mathbf{q}$,

where the technology g satisfies the axioms of closeness, boundedness, strong disposability and convexity as described by Färe \& Primont(1995). This technology can be represented by an input dis tance function, which is defined as:

$\mathrm{D}_{\mathrm{I}}(\mathrm{x}, \mathrm{q}, \mathrm{g}) \quad \sup _{\lambda}\left\{\lambda: \mathrm{x} / \lambda \in \mathrm{L}_{\mathrm{g}}(\mathrm{q}) \geq 1\right\}$

where $\lambda$ denotes the maximum amount by which an input vector can be radially contracted while the output vector remains constant. We assume that every distribution firm employs the best available technol ogy in each period. Thus, the Debreu Farrell input oriented measure of technical efficiency (TE) for firm $i$ in period $t$ is:

$T E\left(x_{i t}, q_{i t}, t\right) \equiv 1 / D_{I}\left(x_{i t}, q_{i t}, t\right)$.

The input distance function has the following features: it is homoge neous of degree one, a non decreasing concave function of inputs, and a non increasingquasi concave function of outputs (see Färe \& Primont, 1995). Linear homogeneity implies that it is possible to normalize all the inputs in the distance function by an arbitrarily chosen input $x_{N_{i t}}$ :

$1 / x_{N_{i t}} \quad D_{I}\left(x_{i t} / x_{N_{i t}}, q_{i t}, t\right) \exp \left(-u_{i t}\right)$,

where $u_{i t} \equiv \ln D_{I}\left(x_{i t} / x_{N_{i t}}, q_{i t}, t\right) \geq 0$. Then, a firm is technically efficient if and only if $u_{i t}=0$ or similarly, $\operatorname{TE}\left(x_{i t}, q_{i t}, t\right)=1$.

Regarding the technology representation, we use a translog functional form to parameterize the distance function. So, we define $v_{i t} \equiv \ln D_{I}\left(x_{i t} / x_{N_{i t}}, q_{i t}, t\right)-T L\left(x_{i t} / x_{N_{i t}}, q_{i t}, t\right)$, where $T L($.$) is the translog$ function. In this case, (9) becomes:

$y_{i t} \quad T L\left(x_{i t} / x_{N_{i t}}, q_{i t}, t\right)+v_{i t}-u_{i t}$, where $y_{i t} \equiv-\ln x_{N_{i} .}$. If any outputs or normalized inputs are stochastic then $v_{i t}$ is stochastic and (10) becomes a standard translog stochastic frontier model. For estimation purposes, the random noise term $v_{i t}$ is assumed to follow a normal distribution and the inefficiency compo nent $u_{i t}$ is assumed to follow a nonnegative distribution. Using the results for individual inefficiencies, TE in each period is calculated as:

$T E_{i t} \quad \exp \left(-u_{i t}\right)$

Changes in productivity may also be computed from a stochastic distance function (see Balk, 2001; Orea, 2002, for a parametric approach to the computation of the Malmquist productivity index). In this context an input oriented Malmquist productivity index can be computed and decomposed into technical efficiency change (TEC), technical change (TC), scale efficiency change (SEC) and an input mixed effect (IME) as follows:

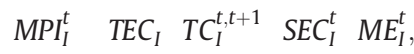

where I denotes the input orientation, and the four components can be defined using a parametric translog specification as: ${ }^{13}$

$\operatorname{TEC}_{I} \frac{D_{I}\left(x^{t}, q^{t}, t\right)}{D_{I}\left(x^{t+1}, q^{t+1}, t+1\right)}$

$T C_{I}^{t, t+1} \frac{D_{I}\left(x^{t+1}, q^{t+1}, t+1\right)}{D_{I}\left(x^{t+1}, q^{t+1}, t\right)}$

$\operatorname{SEC}_{I}^{t} \frac{\breve{D}_{I}\left(x^{t}, q^{t}, t\right)}{\breve{D}_{I}\left(x^{t}, q^{t+1}, t\right)} \frac{D_{I}\left(x^{t}, q^{t+1}, t\right)}{D_{I}\left(x^{t+1}, q^{t}, t\right)}$

$M E_{I}^{t} \frac{\breve{D}_{I}\left(x^{t}, q^{t+1}, t\right)}{\breve{D}_{I}\left(x^{t+1}, q^{t+1}, t\right)} \frac{D_{I}\left(x^{t+1}, q^{t+1}, t\right)}{D_{I}\left(x^{t}, q^{t+1}, t\right)}$,

where $\breve{D}_{I}$ stands for an input distance function associated with constant returns to scale (see Pantzios et al., 2011, for the derivation using the translog input oriented model).

\footnotetext{
${ }^{13}$ Lovell (2003) defines the combined effect of $S E C_{I}^{t}$ and $M E_{I}^{t}$ as the volume effect.
} 
Table 1

Summary statistics.

\begin{tabular}{|c|c|c|c|c|}
\hline Variable & Mean & SD & Minimum & Maximum \\
\hline Residential consumption (MWh) & 785,665 & $1,118,006$ & 13,499 & $4,687,938$ \\
\hline Non-residential consumption (MWh) & 729,120 & $1,138,132$ & 9,069 & $5,637,621$ \\
\hline Residential customers (\#) & 405,457 & 491,828 & 34,365 & $2,247,024$ \\
\hline Non-residential customers (\#) & 40,672 & 57,430 & 2,935 & 294,734 \\
\hline Network length (km) & 16,587 & 15,673 & 232 & 70,795 \\
\hline Customer hours lost (hours) & 89.12 & 101.94 & 6.20 & 580.89 \\
\hline Energy losses (\%) & 16.25 & 7.45 & 4.02 & 38.57 \\
\hline Consumption density (kWh/user) & 2,836 & 1,120 & 436 & 6,642 \\
\hline Customer density (users/km) & 43.41 & 45.42 & 9.85 & 194.42 \\
\hline Total expenses (thousands USD) & 239,034 & 363,063 & 1,395 & $1,768,163$ \\
\hline
\end{tabular}

\section{Data and empirical model}

Information on expenses, consumption, users, network length and quality indicators was collected for a sample of 21 electricity distribu tion firms during the period 1998 2012. The main data sources are CREG,SSPD and annual reports of the companies.Firms in the sample distributed $81 \%$ of the total consumed $\mathrm{kWh}$ in Colombia during the period and share $98 \%$ of total customers in the country. The data set is an unbalanced panel with a total of 246 observations. ${ }^{14}$ Table 1 presents a summary of statistics of the main variables. Monetary values are expressed in thousands of US dollars in real terms of 2012 after deflating by the consumer price index.

From these variables two outputs and three inputs are selected for the specification of the input distance function. Consumption and num ber of customers are the standard outputs in electricity distribution; however, they are usually highly correlated ( 0.95 in our sample) and one of them should be chosen to avoid collinearity problems. In our case, we select the number of users divided into residential $\left(y_{1}\right)$ and non residential users $\left(y_{2}\right)$. Inputs are total expenses $\left(x_{1}\right)$, energy losses $\left(x_{2}\right)$ and customer hours lost $\left(x_{3}\right)$. Total expenses is the sum of operational and capital expenses. The former include administrative, operative and maintenance expenditures and the latter corresponds to the value of new investments in network cables, lines, ducts, tunnels and other machinery, plant and equipment. Considering overall total expenses is desirable for benchmarking electricity utilities (see Giannakis et al., 2005). Moreover, since we also account for quality measures, including total expenses recognizes that distribution firms adopt different strategies mixing capital and operating investment inputs in order to improve quality of service (see (Jamasb et al., 2012)). We also include energy losses and the length of interruptions as inputs where reductions are desirable. This approach has been used before in applications to the electricity sector using SFA models with distance functions (see Growitsch et al., 2005; von Hirschhausen et al., 2006; Tovar et al., 2011). Giannakis et al. (2005) and Yu et al. (2009) have also found these variables to be relevant in performing electric utilities benchmarking analysis explicitly including quality of service. Energy losses is the percentage of energy lost due to technical reasons and customer hours lost is the duration of service interruptions measured in hours per customer. We also include the network length measured in kilometers $(\mathrm{km})$ as a characteristic of the output which is not directly under the control of firms. Finally, we consider two ineffi ciency heterogeneity variables. These are consumption density $\left(z_{1}\right)$ and customer density $\left(z_{2}\right)$. Consumption density is measured as the number of kWh consumed per customer and customer density is measured as the number of users per kilometer. Both variables are expected to affect the inefficiency negatively in the sense that firms

\footnotetext{
14 This is mainly due to missing information in at least one variable for some firms. However, all firms have data for consecutive years and there are no jumps in the time series of the individual companies. Some acquisitions were presented during the period but we keep them as individual firms given that in all cases the acquired companies have kept their name and accountancy.
}

may benefit from serving urban locations and large customers. Goto \& Tsutsui (2008) have found customer density to drive technical ineffi ciency in the US and Melo \& Espinosa (2005) have found both variables to affect inefficiency in Colombia.

We use a translog representation of the technology for the input distance function derived in (10). The specification used captures tech nological change by including a time trend, its square and interactions with inputs and outputsunder the assumption that every distribution firm employs the best available technology in each period. The estimated model with the dynamic specification presented in (1) till (3) is the following:

$$
\begin{aligned}
& \ln x_{1_{i t}}=\alpha_{i}+\sum_{m 1}^{2} \beta_{m} \ln y_{m_{i t}}+\beta_{m+1} \ln k m_{i t}+\sum_{r 1}^{2} \delta_{r} \ln \left(\frac{x_{r_{i t}}}{x_{1_{i t}}}\right) \\
& +\frac{1}{2} \sum_{m 1}^{2} \sum_{n 1}^{2} \beta_{m n} \ln y_{m_{i t}} \ln y_{n_{i t}}+\frac{1}{2} \sum_{r 1}^{2} \sum_{s 1}^{2} \delta_{r s} \ln \left(\frac{x_{r_{i t}}}{x_{1_{i t}}}\right) \ln \left(\frac{x_{s_{i t}}}{x_{1_{i t}}}\right) \\
& +\sum_{m 1}^{2} \sum_{r 1}^{2} \eta_{m r} \ln y_{m_{i t}} \ln \left(\frac{x_{r_{i t}}}{x_{1_{i t}}}\right)+\kappa_{1} t+\frac{1}{2} \kappa_{2} t^{2}+\sum_{m 1}^{2} \phi_{m} t \ln y_{m_{i t}} \\
& +\sum_{r 1}^{2} \varphi_{r} t \ln \left(\frac{x_{r_{i t}}}{x_{1_{i t}}}\right) u_{i t}+v_{i t} \\
& \log u_{i t}=\omega+\sum_{p 1}^{2} \gamma_{p} z_{p_{i t}}+\rho_{i} \log u_{i, t-1}+\xi_{i t} ; \xi_{i t} \sim N\left(0, \sigma_{\xi}^{2}\right) ; t=2 \ldots T \\
& \left.\log u_{i 1}=\frac{\omega+\sum_{p 1}^{2} \gamma_{p} z_{p_{i 1}}}{1 \rho_{i}}+\xi_{i 1} ; \xi_{i 1} \sim N \quad 0, \frac{\sigma_{\xi}^{2}}{1 \rho_{i}^{2}}\right) ; t=1 .
\end{aligned}
$$

Total expenses are used as a numeraire to accomplish linear homo geneity in inputs and cross effects symmetry is imposed by requiring $\beta_{m n}=\beta_{n m}$ and $\delta_{r s}=\delta_{s r}$.

\section{Estimation results}

We estimate four different models derived from (17). The first three models do not account for unobserved technological heterogeneity, that is, $\alpha_{i}=0$. In addition, model (S) restricts $\rho_{i}=0$, so the model becomes static and the inefficiency term follows a log normal distribution with observed heterogeneity in its location parameter. The second model (D) restricts $\rho_{i}=\rho$, which implies a dynamic model with fixed persis tence parameter. The third model (DPH) allows heterogeneous persis tence through $\rho_{i}$. Finally, the fourth model (DPUH) is the complete model in (17), which is dynamic and allows for heterogeneous persis tence and unobserved heterogeneity. Results of the estimations are presented in Table 2.

We observe in all the models the expected signs for inputs and out puts, no relevant technological change and the presence of increasing returns to scale. ${ }^{15}$ Differences in the posterior estimated coefficients are observed, mainly between the static and the dynamic specifications, and between Model DPUH and therest. This suggests that modeling time autocorrelation in the inefficiency component may have effects

${ }^{15}$ Further below we analyze in deep the effects of technical change and scale efficiency along efficiency and productivity by groups of companies with similar characteristics. 
Table 2

Posterior mean and standard deviation of parameter distributions.

\begin{tabular}{|c|c|c|c|c|c|c|c|c|}
\hline \multirow{3}{*}{$\begin{array}{l}\text { Parameters } \\
\text { Parameter }\end{array}$} & \multirow{2}{*}{\multicolumn{2}{|c|}{$\begin{array}{l}\text { Model S } \\
\alpha_{i}=\alpha, \rho_{i}=0\end{array}$}} & \multirow{2}{*}{\multicolumn{2}{|c|}{$\begin{array}{l}\text { Model D } \\
\alpha_{i}=\alpha, \rho_{i}=\rho\end{array}$}} & \multirow{2}{*}{\multicolumn{2}{|c|}{$\begin{array}{l}\text { Model DPH } \\
\alpha_{i}=\alpha, \rho_{i} \neq \rho\end{array}$}} & \multirow{2}{*}{\multicolumn{2}{|c|}{$\begin{array}{l}\text { Model DPUH } \\
\alpha_{i} \neq \alpha, \rho_{i} \neq \rho\end{array}$}} \\
\hline & & & & & & & & \\
\hline & Mean & SD & Mean & SD & Mean & SD & Mean & SD \\
\hline \multicolumn{9}{|l|}{ ID function } \\
\hline$\alpha$ & 13.4149 & 1.2091 & 12.6924 & 0.7935 & 11.4653 & 0.6624 & 11.4045 & 0.5543 \\
\hline$\beta_{1}\left(\ln y_{1}\right)$ & 0.1902 & 0.1215 & 0.0379 & 0.0257 & 0.0346 & 0.0219 & 0.1082 & 0.0266 \\
\hline$\beta_{2}\left(\ln y_{2}\right)$ & 0.0968 & 0.0991 & 0.1200 & 0.0806 & 0.0712 & 0.0530 & 0.0463 & 0.0248 \\
\hline$\beta_{3}\left(\ln x_{2}\right)$ & 0.0115 & 0.0087 & 0.0244 & 0.0135 & 0.0060 & 0.0050 & 0.0149 & 0.0134 \\
\hline$\beta_{4}\left(\ln x_{3}\right)$ & 0.0116 & 0.0088 & 0.0485 & 0.0168 & 0.0232 & 0.0197 & 0.0075 & 0.0056 \\
\hline$\beta_{5}(\ln \mathrm{km})$ & 0.3494 & 0.0739 & 0.3265 & 0.1074 & 0.1265 & 0.0491 & 0.1413 & 0.0625 \\
\hline$\beta_{6}(t)$ & 0.1724 & 0.1217 & 0.0932 & 0.1336 & 0.0616 & 0.0808 & 0.0730 & 0.0684 \\
\hline$\beta_{7}\left(t^{2}\right)$ & 0.0032 & 0.0010 & 0.0046 & 0.0012 & 0.0049 & 0.0006 & 0.0050 & 0.0005 \\
\hline$\phi_{1}\left(1 / 2 \ln y_{1}^{2}\right)$ & 1.0098 & 0.3705 & 1.3391 & 0.5202 & 1.6021 & 0.7925 & 1.5440 & 0.6968 \\
\hline$\phi_{2}\left(\ln y_{1} \ln y_{2}\right)$ & 0.4733 & 0.3262 & 0.8353 & 0.5289 & 1.4377 & 0.6969 & 1.3677 & 0.6227 \\
\hline$\phi_{3}\left(1 / 2 \ln y_{2}^{2}\right)$ & 0.1132 & 0.3291 & 0.2584 & 0.5504 & 1.2588 & 0.6821 & 1.2503 & 0.6303 \\
\hline$\phi_{4}\left(1 / 2 \ln x_{2}^{2}\right)$ & 0.0868 & 0.0463 & 0.0470 & 0.0450 & 0.0105 & 0.0362 & 0.0005 & 0.0346 \\
\hline$\phi_{5}\left(\ln x_{2} \ln x_{3}\right)$ & 0.0951 & 0.0224 & 0.0652 & 0.0321 & 0.0160 & 0.0147 & 0.0037 & 0.0147 \\
\hline$\phi_{6}\left(1 / 2 \ln x_{3}^{2}\right)$ & 0.0302 & 0.0174 & 0.0209 & 0.0194 & 0.0164 & 0.0112 & 0.0138 & 0.0124 \\
\hline$\delta_{1}\left(\ln y_{1} \ln x_{2}\right)$ & 0.2636 & 0.1341 & 0.2488 & 0.1303 & 0.2395 & 0.1451 & 0.1911 & 0.1275 \\
\hline$\delta_{2}\left(\ln y_{2} \ln x_{2}\right)$ & 0.4149 & 0.0977 & 0.3551 & 0.1001 & 0.2212 & 0.1136 & 0.1622 & 0.0967 \\
\hline$\delta_{3}\left(\ln y_{1} \ln x_{3}\right)$ & 0.0175 & 0.0822 & 0.0168 & 0.0767 & 0.0375 & 0.0563 & 0.0140 & 0.0554 \\
\hline$\delta_{4}\left(\ln y_{2} \ln x_{3}\right)$ & 0.2235 & 0.0728 & 0.1163 & 0.0623 & 0.0371 & 0.0542 & 0.0035 & 0.0525 \\
\hline$\kappa_{1}\left(t \ln y_{1}\right)$ & 0.0252 & 0.0211 & 0.0353 & 0.0238 & 0.0192 & 0.0157 & 0.0175 & 0.0141 \\
\hline$\kappa_{2}\left(t \ln y_{2}\right)$ & 0.0238 & 0.0196 & 0.0233 & 0.0211 & 0.0142 & 0.0138 & 0.0150 & 0.0126 \\
\hline$\kappa_{3}\left(t \ln x_{2}\right)$ & 0.0063 & 0.0075 & 0.0032 & 0.0074 & 0.0020 & 0.0047 & 0.0004 & 0.0041 \\
\hline$\kappa_{4}\left(t \ln x_{3}\right)$ & 0.0064 & 0.0040 & 0.0045 & 0.0040 & 0.0022 & 0.0025 & 0.0025 & 0.0022 \\
\hline \multicolumn{9}{|l|}{ Inefficiency } \\
\hline$\omega$ & 1.4049 & 0.8467 & 0.0205 & 0.0050 & 0.0017 & 0.0002 & 0.0028 & 0.0002 \\
\hline$\rho$ & & & 0.8366 & 0.0846 & 0.6532 & 0.0850 & 0.6507 & 0.0868 \\
\hline$\gamma_{1}\left(\ln z_{1}\right)$ & 0.3443 & 0.1008 & 0.0424 & 0.0081 & 0.0317 & 0.0024 & 0.0314 & 0.0168 \\
\hline$\gamma_{2}\left(\ln z_{2}\right)$ & 0.4407 & 0.0838 & 0.1277 & 0.0394 & 0.1258 & 0.0553 & 0.1009 & 0.0452 \\
\hline$\sigma_{v}$ & 0.1653 & 0.0315 & 0.1314 & 0.0194 & 0.0943 & 0.0017 & 0.0977 & 0.0018 \\
\hline$\sigma_{\epsilon}$ & 0.1610 & 0.0517 & 0.0613 & 0.0023 & 0.0406 & 0.0038 & 0.0347 & 0.0029 \\
\hline Posterior eff. & 0.5173 & 0.1205 & 0.5841 & 0.1551 & 0.6478 & 0.2600 & 0.6373 & 0.2420 \\
\hline $\mathrm{DIC}_{3}$ & 119.12 & & 253.28 & & 339.49 & & 349.86 & \\
\hline LPS & 35.79 & & 21.06 & & 9.74 & & 6.53 & \\
\hline
\end{tabular}

on the frontier coefficients and that capturing unobserved technological sources is important in the frontier specification. In general, we observe that the more flexible the model is in terms of accounting for dynamic effects and heterogeneity, the better the values obtained for $\mathrm{DIC}_{3}$ and LPS. Lower values for these criteria suggest better fit and predictive performance. It can be also seen that not only is the average technical efficiency in the whole sector higher in the more flexible models, but also its dispersion. This may suggest that introducing dynamic effects and unobserved heterogeneity sources distinguishes the presence of adjustment costs and heterogeneity from technical inefficiency and also differentiates firms depending on their specific characteristics. These effects can also be observed in Fig. 5 where the evolution of efficiency over time under the four models is plotted. We can also observe that the dynamic models accounting for persistence heteroge neity (DPH and DPUH) identify larger improvements in TE during the period.

In order to understand better the effects of the different specifica tions on the efficiency estimates, we analyze the results at firm level and their evolution over time by comparing the models derived from (17) from the most to the least restrictive. In Fig. 6, we compare the posterior efficiency distribution for a firm with median values for customer and consumption density in 2012 under static and dynamic formulations. We observe that introducing dynamic effects alter not only the location of the distribution, by estimating higher values for

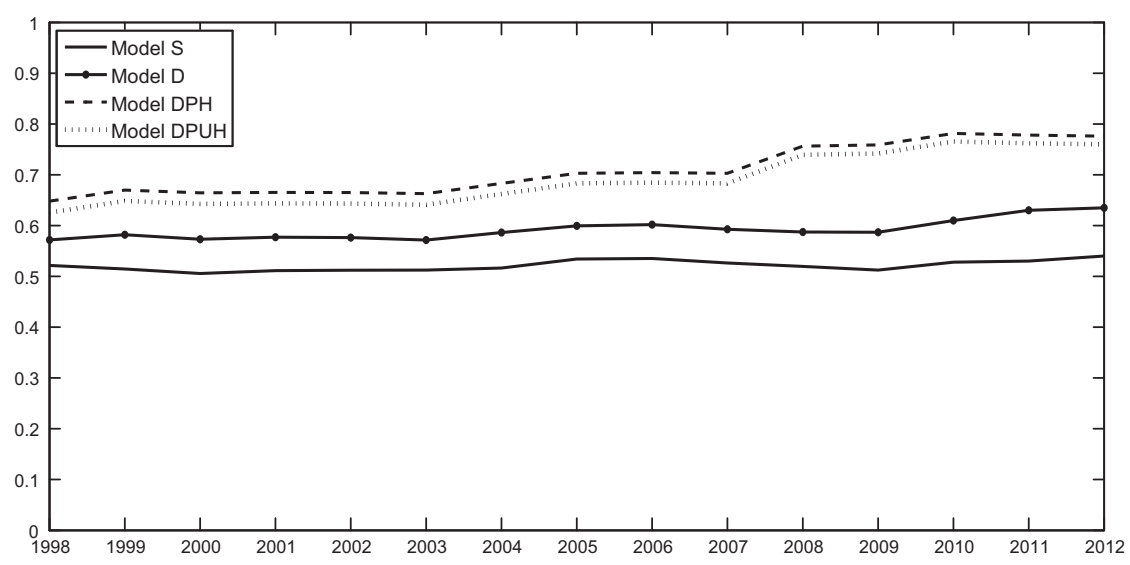

Fig. 5. Evolution of posterior mean TE under different models. 


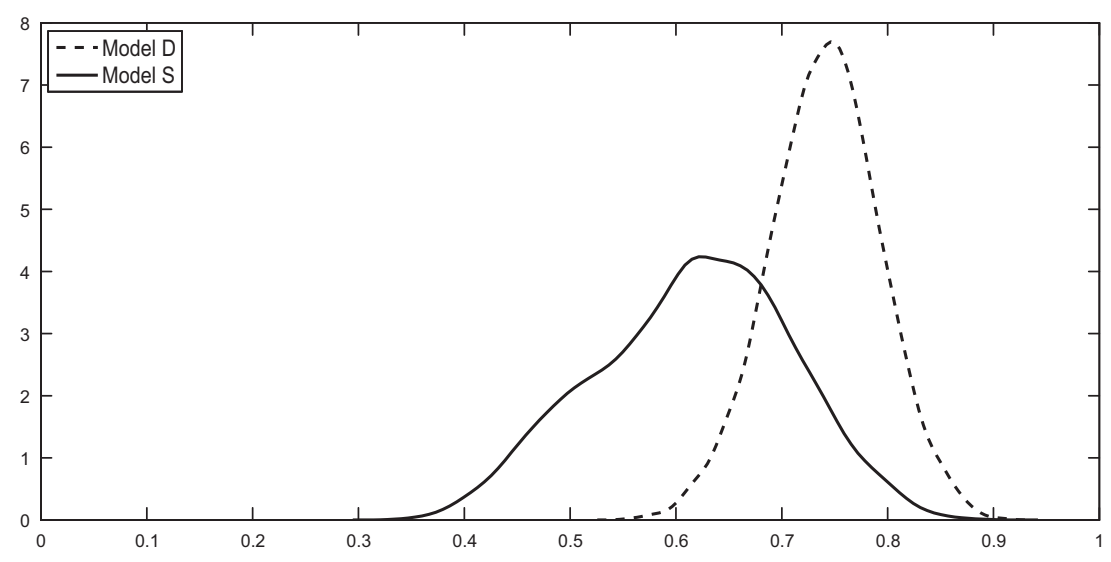

Fig. 6. Posterior efficiency distribution for a representative firm in 2012.

technical efficiency, but also that the dispersion is lower, which allows more certainty on the individual efficiency estimations.

These differences in the posterior distributions also affect the estimation of the evolution of technical efficiency over time. Fig. 7 presents the posterior mean efficiency estimations during the pe riod for two firms, Electrificadora del Quindío (EDEQ) and Empresas Públicas de Medellín (EPM). We observe that for EDEQ, the dynamic specification estimates gains in technical efficiency that are not identi fied under the static model. This may suggest that the improvements made by this firm during the period are more important in relative terms given the presence of high adjustment costs in the sector. In the case of EPM, results imply that, given the adjustment costs faced by all firms in the sector, this firm did not improve enough to identify efficien cy gains. These findings are important from the point of view of the reg ulator because they suggest that firms could not explain poor performance on the basis of modeled adjustment costs.

The dynamic model analyzed assumes that all distribution firms face the same adjustment costs in terms of being able to adjust the same proportion of inefficiency from one period to the next. However, firms with different characteristics may present different adjustment costs, so Model DPH allows for firm specific persistence parameters. Fig. A.2 in the appendix exhibits the $95 \%$ probability intervals for the persistence estimations of every firm. Important differences in the individual posteri or estimations of persistence are found, ranging from 0.31 to 0.99 . This suggests large heterogeneity in the adjustment costs of electricity distributors that could be related to certain characteristics of these firms and the incentiveregulation that they have faced, as is discussed further below. These findings illustrate the importance of accounting for firm specific persistence parameters, which have implications for the effi ciency estimations and their evolution over time as is observed in Fig. 5.

Finally, the full model in (17) is estimated accounting not only for heterogeneous persistence but also for unobserved technological heterogeneity. Although the evolution of efficiency is similar to that estimated under Model DPH (see Fig. 5), Model DPUH identifies unob served firm effects that distinguish them in terms of the estimated efficiency. Fig. 8 compares the posterior efficiency distributions for a low and a high efficient firm under models DPH and DPUH. ${ }^{16}$ We observe that their posterior distributions move and shrink, implying a reduction in the uncertainty of the individual estimations. It is also important to notice that estimations of firm specific persistence param eters do not present important changes compared to those obtained in Model DPH.

Focusing on our preferred model (DPUH), we can identify some links between differences in adjustment costs and firm characteristics. We plot in Fig. 9 the average posterior distributions of the persistence

\footnotetext{
${ }^{16}$ The selected firms are Central Hidroeléctrica de Caldas (CHC) and Empresa Distribuidora del Pacífico (DISPAC).
}

parameter by groups of firms. In general, we observe that firms with a higher proportion of rural and small customers present lower adjustment costs than those which are mainly urban and serve larger customers. In contrast, by type of ownership and number of customers, no major differ ences can be observed between firms in terms of inefficiency persistence. This would imply that rural firms and those with small customers have been able to adapt more easily towards optimal performance.

Differences between groups of Colombian utilities are also observed in terms of efficiency. Fig. 10 exhibits the average posterior technical efficiency during the period by groups of firms. We observe that mainly urban distributors and firms serving high consumption customers have been more efficient during the period than their counterparts. Although differences are smaller, this is also the case of private and large distributors.

However, what it is more interesting in our dynamic analysis is the change that these firms have exhibited from 1998 to 2012 in terms of efficiency and productivity. We compute the MPI and its decomposition as described in Eqs. (12) till (16), and present the results by group of firms in Table 3. We observe that all types of firms except those in urban areas and serving high consumption customers have increased their productivity during the period. This improvement has been driven in all the cases by increases in technical efficiency, which has compen sated the technological regress suggested by the results for technical change for all firms. Regarding scale efficiency change, only private, rural and firms with low consumption customers exhibit some improvement in terms of operating at the efficient scale. Finally, the input mix effect exhibit values very close to 1 for all groups which suggests that changes in the input mix during the period have kept scale efficiency almost unaltered.

In general, rural firms and those serving low consumption customers exhibit very important increases in productivity during the post reform period explained by improvements in their scale efficiency but mainly due to large increases in technical efficiency. These firms are also those exhibiting lower inefficiency persistence and therefore those with higher scope for improvement.

This relationship between inefficiency persistence and changes in technical efficiency is presented in Fig. 11 where the average posterior inefficiency persistence is plotted against their average posterior TE in 1998 and 2012 for every identified group of firms. We observe that firms with high inefficiency persistence have barely changed their TE. This is particularly noticeable for urban distributors and firms with high consumption customers. On the other hand, rural companies and firms with more small customers seem to catch up with their coun terparts in terms of efficiency during the period. ${ }^{17}$ This suggests that in centives introduced by the regulator during the period, in terms of

\footnotetext{
17 In Table A.1 of Appendix A we present these results for each firm along with other firm characteristics.
} 

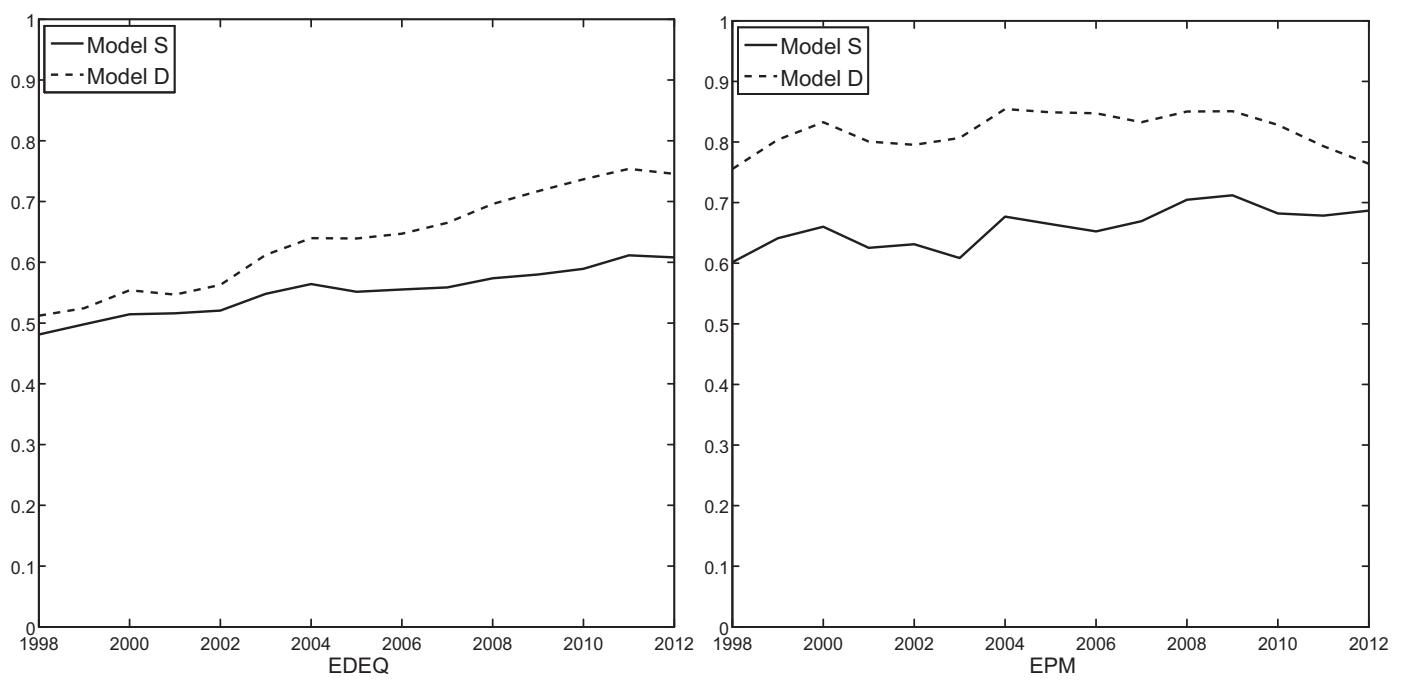

Fig. 7. Evolution of posterior mean efficiencies for EDEQ and EPM.
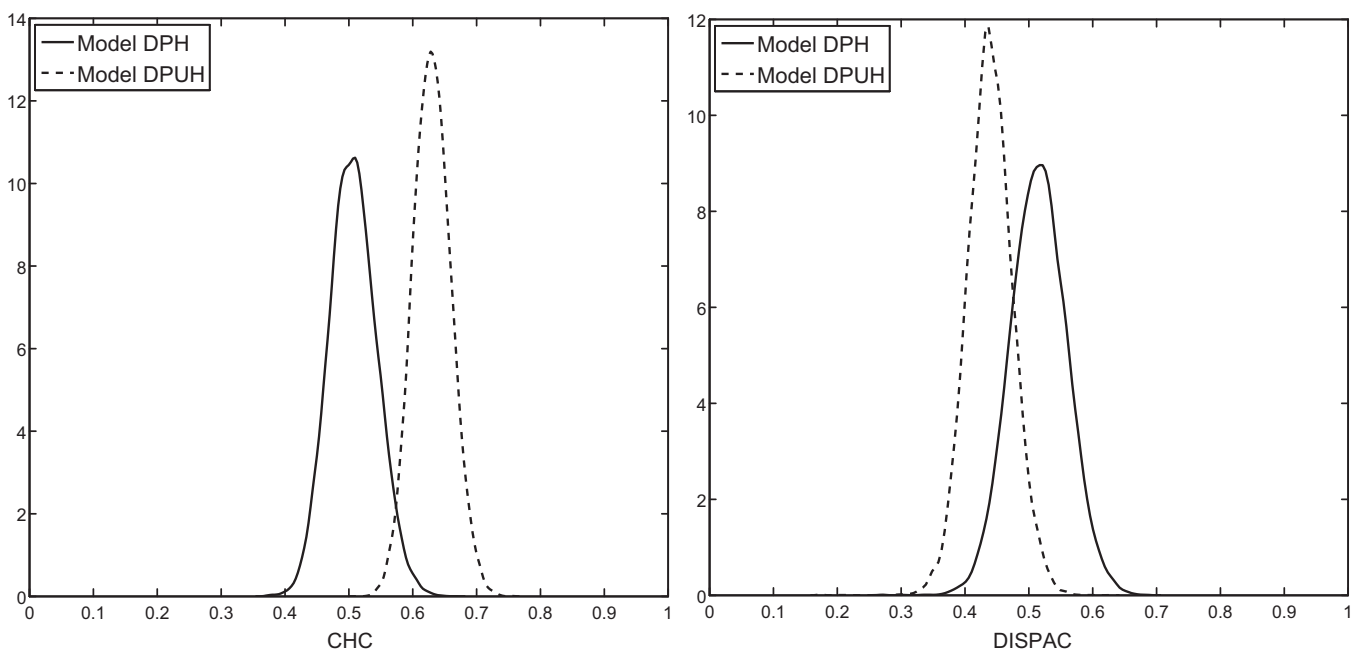

Fig. 8. Posterior efficiency distributions for CHC and DISPAC.

service quality, have helped distributors with low consumption customers and in rural areas to improve their efficiency but that they have not been effective for their counterparts, which in absence of new incentives may become stuck in terms of technical efficiency.

\section{Conclusions}

The electricity reform in Colombia introduced the separation of activities in the electricity sector and set the conditions for privatization and competition. In general, the reform has had positive effects on the ability of the sector to overcome extreme weather conditions and meet demand requirements. However, for distribution companies, com petition and privatization have been slow processes and the users did not benefit from improvements in service quality for the first ten years after the reform. In fact, previous studies measuring consequences of the reform on efficiency have not found evidence of improvements, although large differences in efficiency have been found among firms.

This may indicate the presence of high adjustment costs in the sector in Colombia and important heterogeneity factors among distributors. We include these conditions in a stochastic frontier model that accounts for dynamic effects and unobservedheterogeneity. Our findings suggest high inefficiency persistence in the sector that could be related to adjustment costs and inadequate incentive regulation. However, important differences are found among firms. In particular, firms operating mainly in rural markets and serving small customers present lower adjustment costs than firms with the opposite characteristics. This condition has allowed these firms to catch up urban firms and firms serving large users, which should draw the attention of the regulator because they seem to be stuck in terms of technical efficiency. In fact, customer density and consumption density are found to be important inefficiency drivers in the sector, and sources of unobserved heterogeneity are relevant in distinguishing heterogeneity from ineffi ciency and identifying differences among firms.

Our findings may be helpful for the Colombian regulator and the Ministry of Mines and Energy, which have been recently working on the composition of groups of distribution firms that would share the same prices. ${ }^{18}$ These groups have been formed following geographical criteria. However, our results suggest that the design of these groups should mainlyconsider the inefficiency persistence level of each firm and their characteristics in terms of customer density and consumption density.

Overall, efficiency in the Colombian distribution sector has been found to exhibit improvements. However, efficiency gains can only be

\footnotetext{
18 CREG resolution 058 of 2008 and Ministry of Mines and Energy resolutions: 182306 of 2009, 181347 of 2010, 180686 of 2011 and 180574 of 2012.
} 
Type of ownership
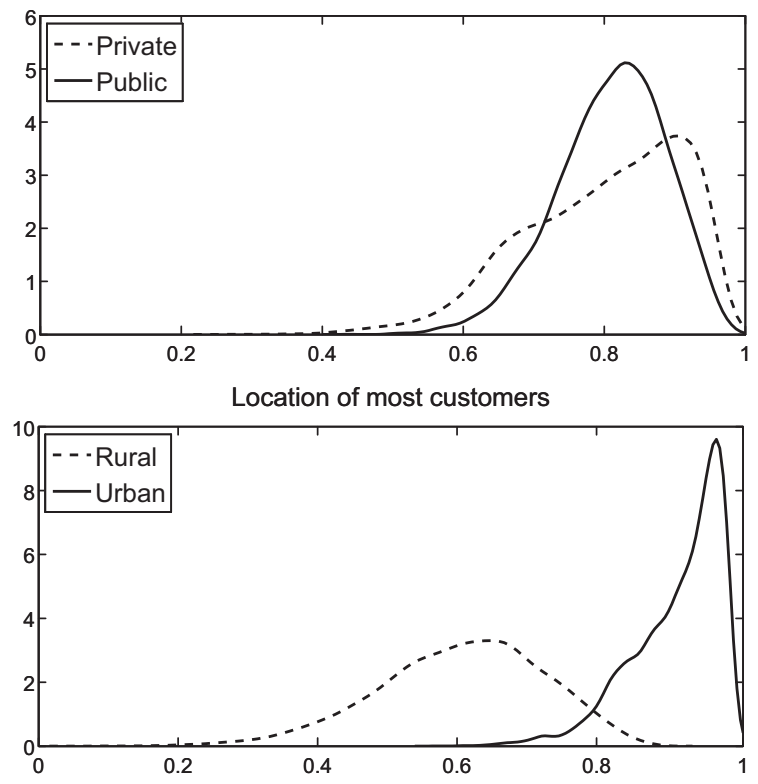

Number of customers
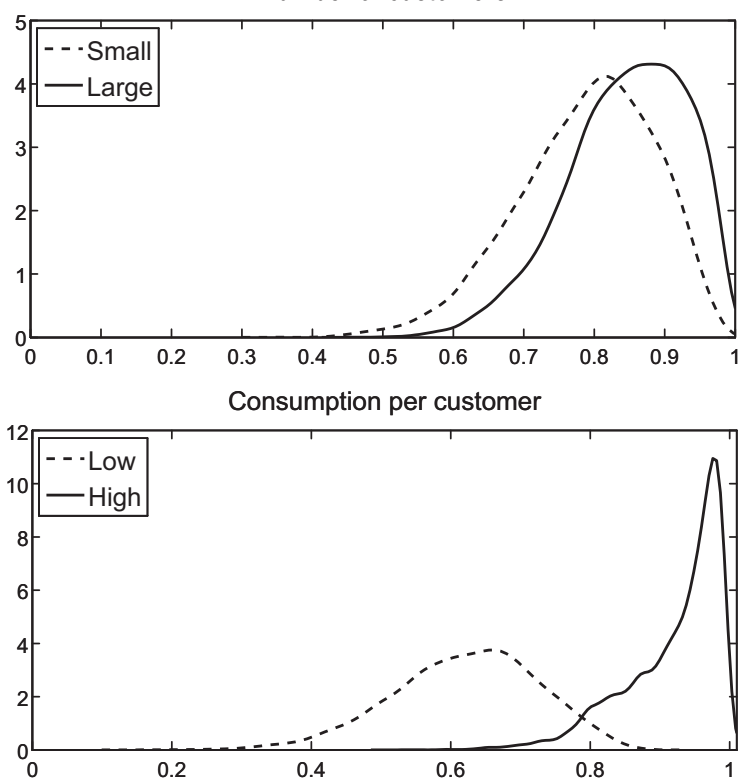

Fig. 9. Average posterior distribution of $\rho_{i}$ by groups of firms.
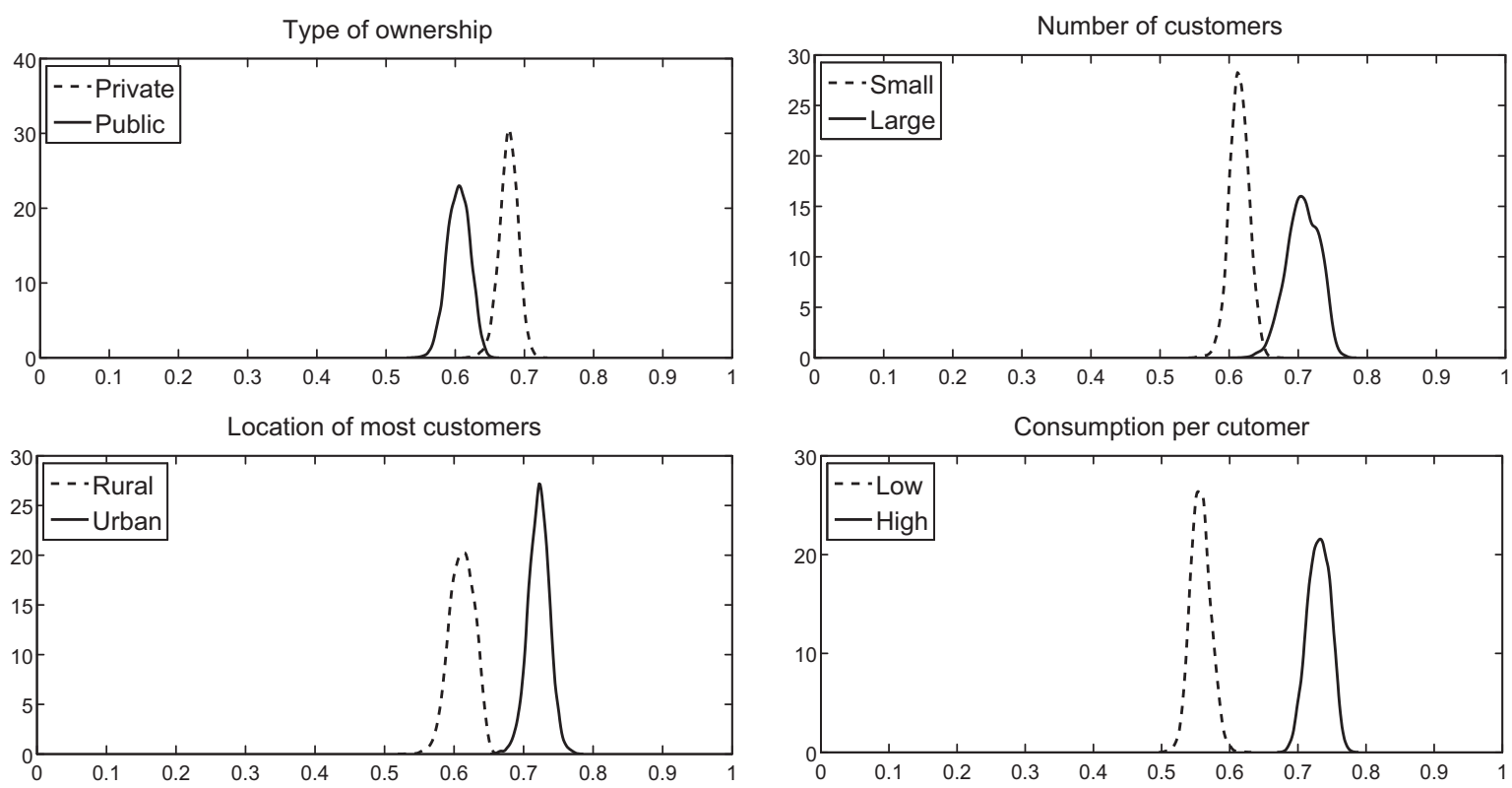

Fig. 10. Average posterior distribution of efficiency by groups of firms.

clearly identified in the last five years. This period coincides with the main reductions in the length of interruptions and energy losses, and the highest rates of increase in the number of customers. Although

Table 3

Decomposition of the Malmquist productivity index by groups of firms.

\begin{tabular}{llllll}
\hline Firms & TEC & TC & SEC & ME & MPI \\
\hline Private & 1.0930 & 0.9399 & 1.0167 & 0.9956 & 1.0445 \\
Public & 1.1694 & 0.9417 & 0.9736 & 1.0023 & 1.0722 \\
Small & 1.2714 & 0.9419 & 0.9753 & 1.0024 & 1.1680 \\
Large & 1.1932 & 0.9386 & 0.9572 & 0.9996 & 1.0720 \\
Rural & 1.4723 & 0.9384 & 1.0343 & 1.0007 & 1.4290 \\
Urban & 1.0396 & 0.9407 & 0.9694 & 1.0058 & 0.9480 \\
Low cons & 1.4701 & 0.9440 & 1.0102 & 0.9987 & 1.4019 \\
High cons & 0.9986 & 0.9387 & 0.9666 & 1.0073 & 0.9061 \\
Total & 1.2161 & 0.9388 & 1.0332 & 0.9972 & 1.1795 \\
\hline
\end{tabular}

very preliminary, these results may favor the recent incentive regula tion policies for improving quality of service and reducing energy losses. Nevertheless, the last five years have also been characterized by impor tant increases in the electricity tariff for regulated users. Not only has the tariff per $\mathrm{kWh}$ increased during the period, but also the proportion derived from distribution costs has increased relative to the other tariff components. This implies that Colombian users are now receiving a bet ter service but that they are paying the costs of these improvements via higher tariffs. ${ }^{19}$ These results suggest that incorporating willingness to pay into the efficiency analysis of the Colombian distribution sector would be of interest for future research.

19 In fact, for the case of UK, Yu et al. (2009) have found the social cost of outages to be considerably higher than the utilities' incentives. 

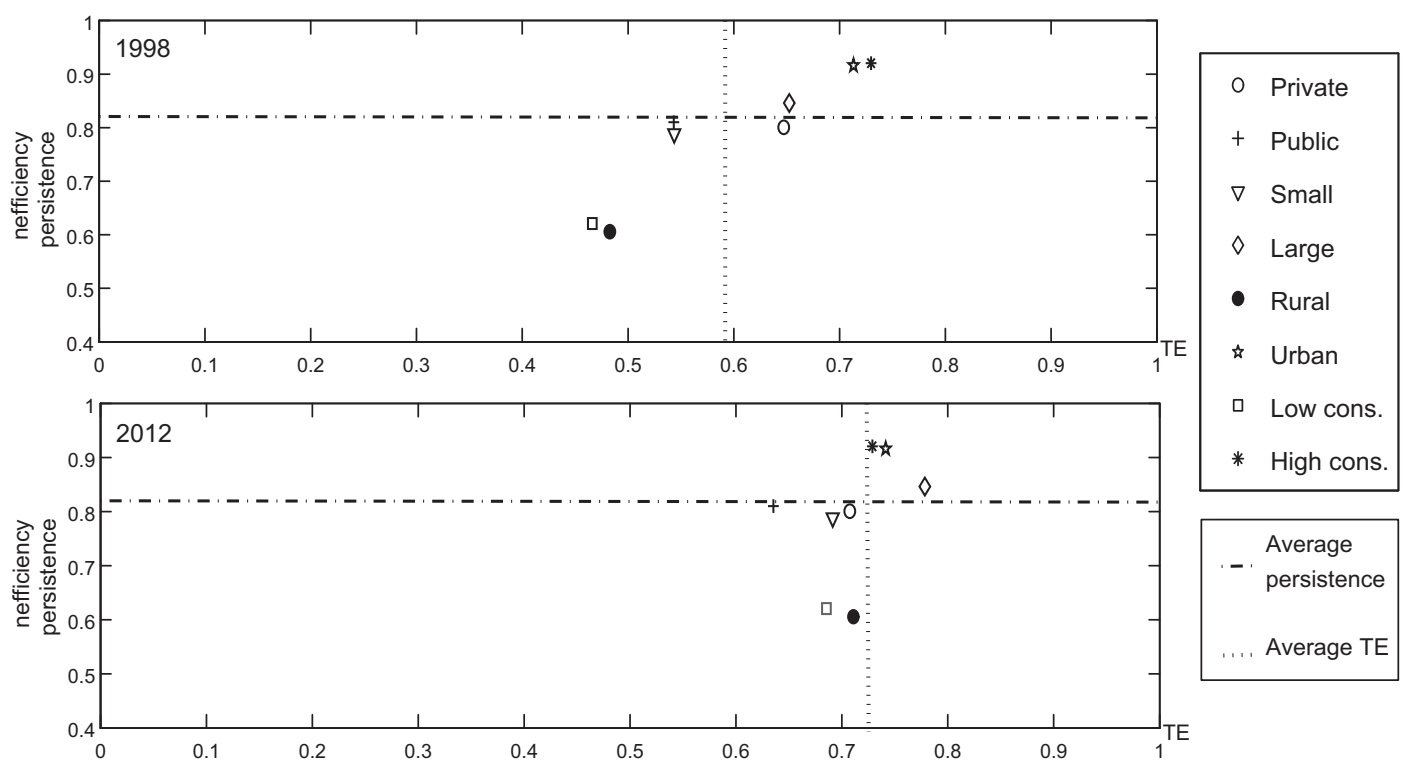

Fig. 11. Inefficiency persistence and technical efficiency by groups of firms (1998 and 2012).

\section{Appendix A}
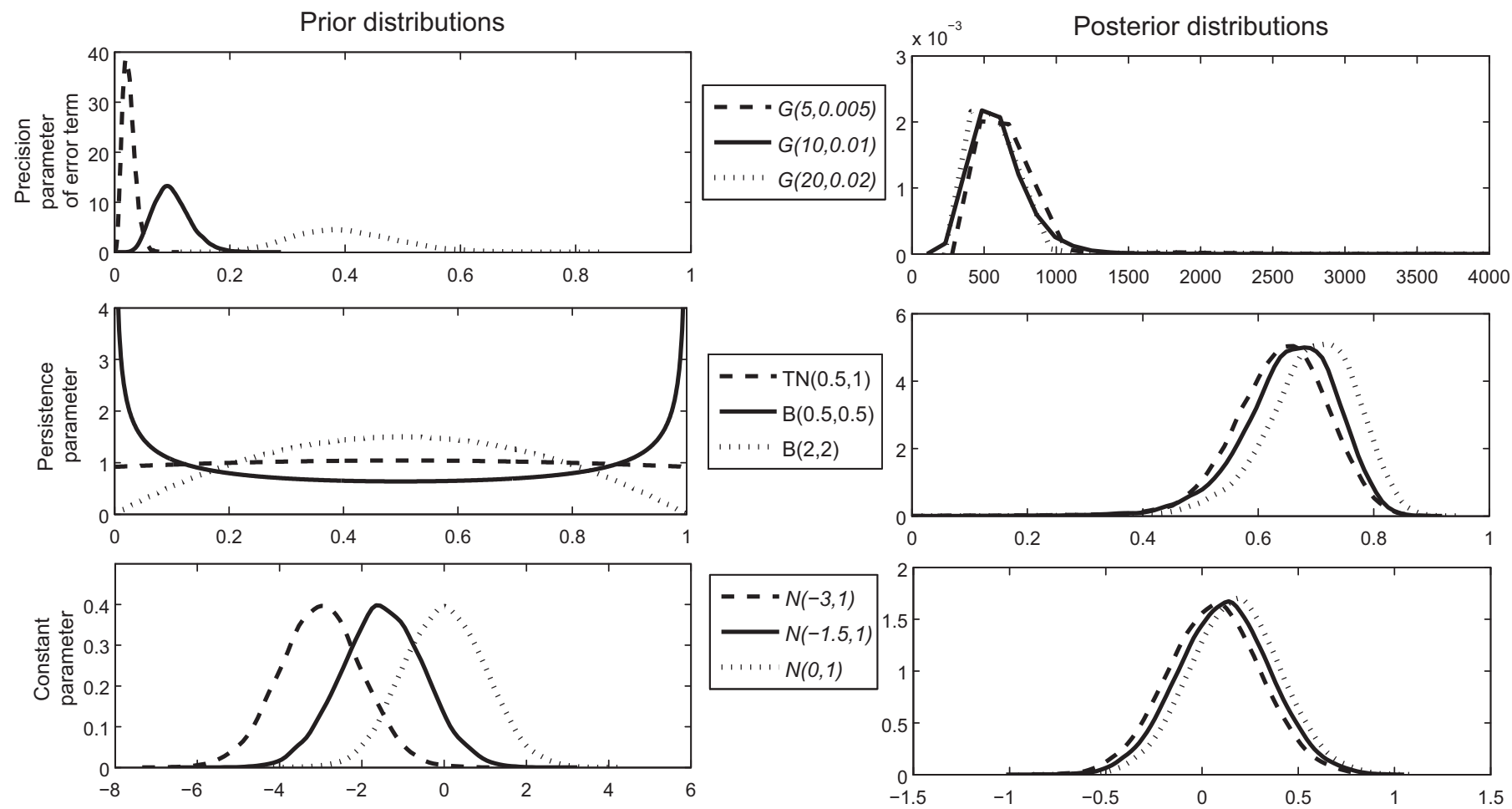

Fig. A.1. Sensitivity of posterior results to changes in prior distributions for the parameters in the inefficiency specification of Model DPUH $\sigma_{\xi}{ }^{2}, \rho$ and $\omega$. 


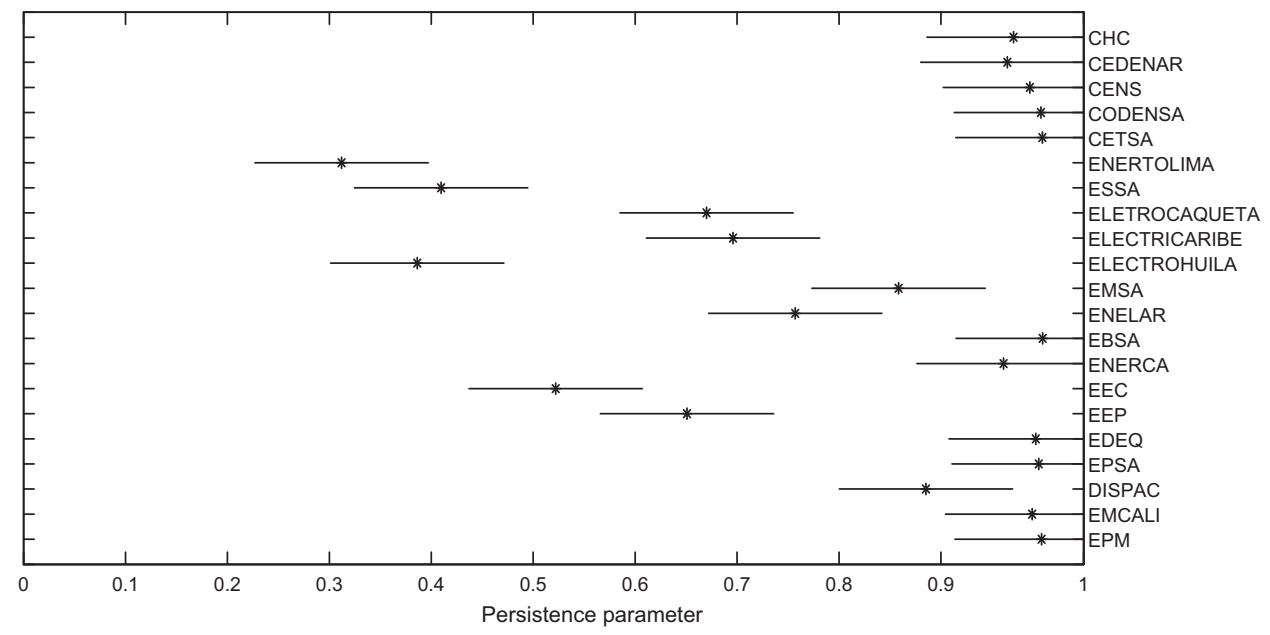

Note: See Table A.1 for the list of firms and acronyms

Fig. A.2. 95\% probability intervals for firm specific persistence parameters under Model DPH.

Table A.1

Posterior mean estimations of TE and persistence under model DPUH, customer density and consumption density by firm.

\begin{tabular}{|c|c|c|c|c|}
\hline Firm & Average TE 1998-2012 & Inefficiency persistence & Cust. dens. (users $/ \mathrm{km}$ ) & Cons. dens. (kWh/user) \\
\hline Central Hidroeléctrica de Caldas S.A. E.S.P. (CHC) & 0.5520 & 0.9713 & 31199 & 341 \\
\hline Centrales Eléctricas de Nariño S.A. E.S.P. (CEDENAR) & 0.3045 & 0.9651 & 23072 & 474 \\
\hline Centrales Eléctricas del Norte de Santander S.A. E.S.P. (CENSA) & 0.6118 & 0.9872 & 13996 & 94 \\
\hline CODENSA S.A. E.S.P. (CODENSA) & 0.9894 & 0.9981 & 47207 & 830 \\
\hline Compañía de Electricidad de Tuluá S.A. E.S.P. (CETSA) & 0.9892 & 0.9996 & 47355 & 2116 \\
\hline Compañía Energética del Tolima S.A. E.S.P. (ENERTOLIMA) & 0.4667 & 0.3120 & 13205 & 77 \\
\hline Electrificadora de Santander S.A. E.S.P. (ESSA) & 0.4624 & 0.4096 & 33639 & 152 \\
\hline Electrificadora del Caquetá S.A. E.S.P. (ELECTROCAQUETA) & 0.4977 & 0.6700 & 20120 & 209 \\
\hline Electrificadora del Caribe S.A. E.S.P. (ELECTRICARIBE) & 0.4506 & 0.6960 & 40553 & 336 \\
\hline Electrificadora del Huila S.A. E.S.P. (ELECTROHUILA) & 0.4720 & 0.3862 & 16663 & 94 \\
\hline Electrificadora del Meta S.A. E.S.P. (EMSA) & 0.5033 & 0.8584 & 39699 & 261 \\
\hline Empresa de Energía de Arauca E.S.P. (ENELAR) & 0.4260 & 0.7571 & 21334 & 981 \\
\hline Empresa de Energía de Boyacá S.A. E.S.P. (EBSA) & 0.9960 & 0.9999 & 21356 & 237 \\
\hline Empresa de Energía de Casanare S.A. E.S.P. (ENERCA) & 0.3677 & 0.9615 & 13352 & 110 \\
\hline Empresa de Energía de Cundinamarca S.A. ESP (EEC) & 0.4760 & 0.5221 & 42579 & 153 \\
\hline Empresa de Energía de Pereira S.A. E.S.P. (EEP) & 0.4913 & 0.6509 & 21193 & 299 \\
\hline Empresa de Energía del Quindío S.A.E.S.P. (EDEQ) & 0.6487 & 0.9930 & 33337 & 452 \\
\hline Empresa de Energía del Pacífico S.A. E.S.P. (EPSA) & 0.7303 & 0.9959 & 50925 & 269 \\
\hline Empresa Distribuidora del Pacífico S.A. E.S.P. (DISPAC) & 0.4233 & 0.8853 & 22464 & 475 \\
\hline Empresas Municipales de Cali E.I.C.E. E.S.P. (EMCALI) & 0.7328 & 0.9895 & 61707 & 2331 \\
\hline Empresas Públicas de Medellín E.S.P. (EPM) & 0.9015 & 0.9988 & 82735 & 389 \\
\hline
\end{tabular}

\section{Appendix B. Supplementary data}

Supplementary data to this article can be found online at http://dx. doi.org/10.1016/j.eneco.2014.08.024.

\section{References}

Ahn, S., Good, D., Sickles, R., 2000. Estimation of long-run inefficiency levels: a dynamic frontier approach. Econ. Rev. 19, 461-492.

Aigner, D., Lovell, C., Schmidt, P., 1977. Formulation and estimation of stochastic frontier production function models. J. Econ. 6, 21-37.

Balk, B.M., 2001. Scale efficiency and productivity change. J. Prod. Anal. 15, 159-183.

Battese, G., Coelli, T., 1992. Frontier production function, technical efficiency and panel data: with application to paddy farmers in India. J. Prod. Anal. 3, 153-169.

Celeux, G., Forbes, F., Robert, C., Titterington, D., 2006. Deviance information criteria for missing data models. Bayesian Anal. 4, 651-674.

Cornwell, C., Schmidt, P., Sickles, R., 1990. Production frontiers with cross-sectional and time-series variation in efficiency levels. J. Econ. 46, 185-200.

Dyner, I., Arango, S., Larsen, E., 2006. Understanding the Argentinean and Colombian electricity markets. Electricity Market Reform: An International Perspective. Elsevier Ltd., pp. 595-616, (chapter 17).
Emvalomatis, G., 2012. Adjustment and unobserved heterogeneity in dynamic stochastic frontier models. J. Prod. Anal. 37, 7-16.

Emvalomatis, G., Stefanou, S., Lansink, A., 2011. A reduced-form model for dynamic efficiency measurement: application to dairy farms in Germany and The Netherlands. Am. J. Agric. Econ. 93, 131-174.

Färe, R., Primont, D., 1995. Multi-output Production and Duality: Theory and Applications. Kluwer Academic Publishers, Netherlands.

Ferreira, J., Steel, M., 2007. Model comparison of coordinate-free multivariate skewed distributions with an application to stochastic frontiers. J. Econ. 137, 641-673.

Galán, J., Veiga, H., Wiper, M., 2014. Bayesian estimation of inefficiency heterogeneity in stochastic frontier models. J. Prod. Anal. 42, 85-101.

Galán, J., Veiga, H., Wiper, M., 2014. Dynamic effects in inefficiency: evidence from the Colombian banking sector. Eur. J. Oper. Res. http://dx.doi.org/10.1016/j.ejor.2014.07. 005 (in press).

Giannakis, D., Jamasb, T., Pollitt, M., 2005. Benchmarking and incentive regulation of quality of service: an application to the UK electricity distribution networks. Energy Policy 33, 2256-2271.

Good, I., 1952. Rational decisions. J. R. Stat. Soc. Ser. B 14, 107-114.

Goto, M., Tsutsui, M., 2008. Technical efficiency and impacts of deregulation: an analysis of three functions in U.S. electric power utilities during the period from 1992 through 2000. Energy Econ. 30, 15-38.

Greene, W., 2005. Reconsidering heterogeneity in panel data estimators of the stochastic frontier model. J. Econ. 126, 269-303. 
Griffin, J., Steel, M., 2004. Semiparametric Bayesian inference for stochastic frontier models. J. Econ. 123, 121-152.

Griffin, J., Steel, M., 2007. Bayesian stochastic frontier analysis using WinBUGS. J. Prod. Anal. 27, 163-176.

Growitsch, T., Jamasb, T., Pollitt, M., 2005. Quality of service, efficiency and scale in network industries: an analysis of European electricity distribution. Appl. Econ. 41, 2555-2570.

Growitsch, T., Jamasb, T., Wetzel, H., 2012. Efficiency effects of observed and unobserved heterogeneity: evidence from Norwegian electricity distribution networks. Energy Econ. 34, 542-548.

Hattori, T., 2002. Relative performance of U.S. and Japanese electricity distribution: an application of stochastic frontier analysis. J. Prod. Anal. 18, 269-284.

von Hirschhausen, C., Cullmann, A., Kappeler, A., 2006. Efficiency analysis of German electricity distribution utilities - non-parametric and parametric tests. Appl. Econ. 38, 2553-2566.

Huang, T., Chen, Y., 2009. A study on long-run inefficiency levels of a panel dynamic cost frontier under the framework of forward-looking rational expectations. J. Bank. Financ. 33, 842-849.

Jamasb, T., Orea, L., Pollitt, M., 2012. Estimating the marginal cost of quality improvements: the case of the UK electricity distribution companies. Energy Econ. 34, 1498-1506.

Koop, G., Steel, M., Osiewalski, J., 1995. Posterior analysis of stochastic frontier models using Gibbs sampling. Comput. Stat. 10, 353-373.

Kopsakangas-Savolainen, M., Svento, R., 2011. Observed and unobserved heterogeneity in stochastic frontier models: an application to the electricity distribution industry. Energy Econ. 33, 304-310.

Kumbhakar, S., 1990. Production frontiers, panel data, and time-varying technical inefficiency. J. Econ. 46, 201-212.

Larsen, E., Dyner, I., Bedoya, L., Franco, C., 2004. Lessons from deregulation in Colombia: successes, failures and the way ahead. Energy Policy 32, 1767-1780.

Lee, Y., Schmidt, P., 1993. The Measurement of Productive Efficiency: Tech- niques and Applications, Chapter Production Frontier Model with Flexible Tem- poral Variation in Technical Inefficiency. Oxford University Press, Inc.

Lovell, C.A.K., 2003. The decomposition of Malmquist productivity indexes. J. Prod. Anal. $20,437-458$

Li, Y., Zeng, T., Yu, J., 2012. Robust deviance information criterion for latent variable models. Singapore Management University, Research Collection School of Economics (Open Access)Paper 1403.
Meeusen, W., van den Broeck, J., 1977. Efficiency estimation from Cobb-Douglas production functions with composed errors. Int. Econ. Rev. 8, 435-444.

Melo, L., Espinosa, N., 2005. Ineficiencia en la distribución de energía eléctrica: una aplicación de las funciones de distancia estocástica. Ensayos sobre Política Económica, Banco de la República. No. 49.

Mota, R., 2003. The restructuring and privatisation of electricity distribution and supply business in Brazil: a social cost-benefit analysis. CMI Working Paper EP16. University of Cambridge.

Orea, L., 2002. Parametric decomposition of a generalized Malmquist productivity index. J. Prod. Anal. 18, 5-22.

Pantzios, C.J., Karagiannis, G., Tzouvelekasin, V., 2011. Parametric decomposition of the input-oriented Malmquist productivity index: with an application to Greek aquaculture. J. Prod. Anal. 36, 21-31.

Pérez-Reyes, R., Tovar, B., 2009. Measuring efficiency and productivity change (PTF) in the Peruvian electricity distribution companies after reforms. Energy Policy 37, 2249-2261.

Pollitt, M., 2004. Electricity reform in Chile: lessons for developing countries. J. Netw. Ind. 5, 221-262.

Pollitt, M., 2008. Electricity reform in Argentina: lessons for developing countries. Energy Econ. 30, 1536-1567.

Pombo, C., Taborda, R., 2006. Performance and efficiency in Colombia's power distribution system: effects of the 1994 reform. Energy Econ. 28, 339-369.

Richardson, S., 2002. Discussion of Spiegelhalter et al. J. R. Stat. Soc. Ser. B 64, 626-627.

Spiegelhalter, D., Best, N., Carlin, B., van der Linde, A., 2002. Bayesian measures of model complexity and fit. J. R. Stat. Soc. 64, 583-616.

Ter-Martirosyan, A., Kwoka, J., 2010. Incentive regulation, service quality, and standards in U.S. electricity distribution. J. Regul. Econ. 38, 258-273.

Tovar, B., Ramos-Real, F., Fagundes de Almeida, E., 2011. Firm size and productivity. Evidence from the electricity industry in Brazil. Energy Policy 39, 826-833.

Tsionas, E., 2006. Inference in dynamic stochastic frontier models. J. Appl. Econ. 21, 669-676.

van den Broeck, J., Koop, G., Osiewalski, J., Steel, M., 1994. Stochastic frontier models: Bayesian perspective. J. Econ. 61, 273-303.

Yu, W., Jamasb, T., Pollitt, M., 2009. Willingness to pay for quality service: an application to efficiency analysis of the UK electricity distribution utilities. Energy J. 30, 1-48. 